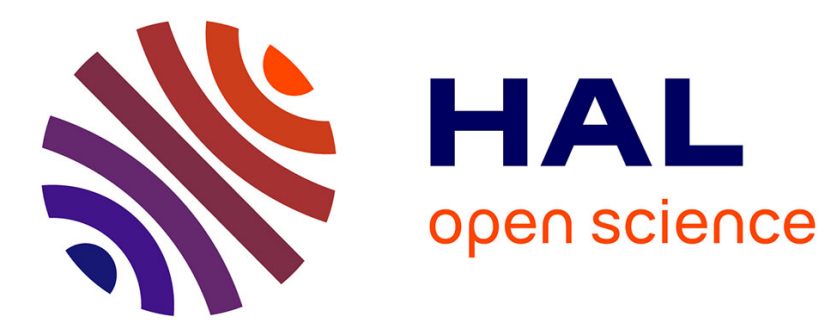

\title{
HCF of AA7050 alloy containing surface defects: Study of the statistical size effect
}

Foued Abroug, Etienne Pessard, Guenaël Germain, Franck Morel

\section{To cite this version:}

Foued Abroug, Etienne Pessard, Guenaël Germain, Franck Morel. HCF of AA7050 alloy containing surface defects: Study of the statistical size effect. International Journal of Fatigue, 2018, 110, pp.8194. 10.1016/j.ijfatigue.2018.01.012 . hal-02282721

\section{HAL Id: hal-02282721 \\ https://hal.science/hal-02282721}

Submitted on 10 Sep 2019

HAL is a multi-disciplinary open access archive for the deposit and dissemination of scientific research documents, whether they are published or not. The documents may come from teaching and research institutions in France or abroad, or from public or private research centers.
L'archive ouverte pluridisciplinaire HAL, est destinée au dépôt et à la diffusion de documents scientifiques de niveau recherche, publiés ou non, émanant des établissements d'enseignement et de recherche français ou étrangers, des laboratoires publics ou privés. 


\title{
HCF of AA7050 alloy containing surface defects: Study of the statistical size effect
}

\author{
Foued Abroug*, Etienne Pessard, Guenaël Germain, Franck Morel \\ LAMPA, Arts et Métiers ParisTech Angers, 2 Bd du Ronceray, 49035 Angers, France
}

Keywords:

Surface defect

High cycle fatigue

Kitagawa-Takahashi diagram

Volume effect

Size effect

Weakest link concept

AA7050 alloy

\section{A B S T R A C T}

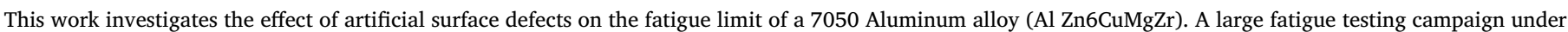

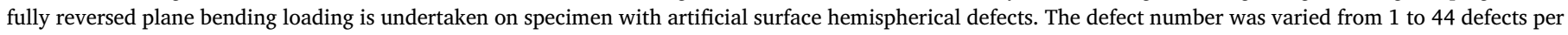

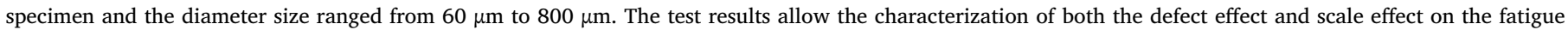

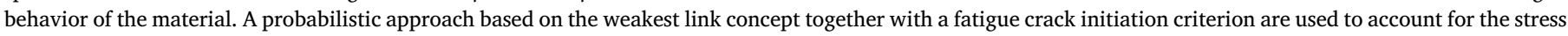

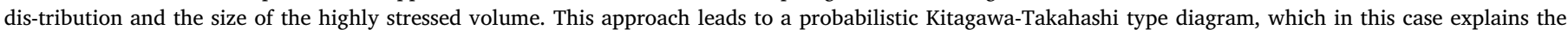

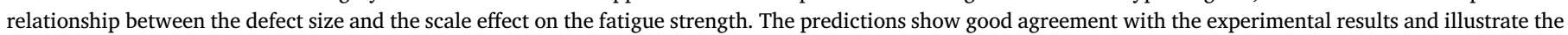
im-portance of taking the scale effect into account when designing components containing different surface defects types or roughness patterns.

\section{Introduction}

The fatigue data transferability from laboratory specimens to real industrial components or structures is often a tough task due to the high number of parameters affecting the fatigue strength. The loading mode, the microstructural heterogeneities, the defects and residual stresses induced by the manufacturing process, the gradient and the size of the loaded volume are known to greatly affect the fatigue response. For instance, for the same size and geometry of a specimen or a component, it is well known that the loading mode affects the fatigue limit: a difference is usually observed between torsion, uniaxial tension, biaxial tension, rotating or plane bending. These differences can be explained by the stress state and by the macroscopic gradient introduced in the different cases. When extra stress concentrators are introduced (notch, welded joint ...), the local gradient is affected and if the critical fatigue area is concerned, the resulting macroscopic fatigue strength can be substantially altered.

It has long been recognized that fatigue limit depends on the spatial stress distribution (volumetric stress distribution) and also on the size of the loaded component. However, the so-called "stress gradient effect" and "size effect" are very closely linked and lead sometimes to confusions. A good review of these two effects was proposed by Papadopoulos and Panoskaltsis [1]. In this paper, the authors try to carefully explain the difference between the pure "size effect" and the pure "stress gradient effect". They clearly show that, very often, the two effects can act concurrently. Let us take the example of a smooth cylindrical specimen submitted to a rotating or plane bending fatigue loading. An increase of the specimen radius leads at the same time to a decrease of the stress gradient and to an increase of the loaded volume. In this case, the two effects are simultaneous. On the contrary, when a smooth cylindrical specimen of constant radius is subjected to a uniaxial tension loading and its length is increased, there is no stress gradient and the stressed volume gets bigger. All the investigations in the literature regarding that kind of experimental studies lead to the well-known conclusions:

- "The higher the gradient, the higher the fatigue strength"

- "The higher the stressed volume, the lower the fatigue strength"

In short, although they are confused in the literature, the two effects are distinct phenomena that need to be accounted for by different approaches.

The models dedicated to the statistical size effect are often of two types. The first type of approach, usually used for nonmetallic inclusions in steel, is based on the extreme value analysis of the inclusion population. It predicts the maximum defect size that is possible to be observed in a given volume $[2,3]$. The details of the methodology are described in the ASTM standard [4]. The second type of approach

\footnotetext{
* Corresponding author.

E-mail address: Foued.Abroug@ensam.eu (F. Abroug).
} 
makes use of a two scale probabilistic model to consider the stressed volume size. Applying the weakest link concept [5], the failure probability of a component is calculated from the failure probability of several elementary volumes [6].

The models dealing with the gradient effect in a deterministic way are often built by using a non local approach like the one initially proposed by Taylor $[7,8]$. The efficiency of non local approaches has been demonstrated in a number of applications, for instance for notched components [9], specimens containing internal defects [10] or surface defects [11].

Even though several models considering the size effect and the gradient effect are available, just a few of them [12-14] incorporate both effects in a combined manner as discussed in [15]. Moreover, the role of material defects is most of the time investigated by considering the most critical one and by applying a deterministic criterion like in the work of Murakami [2]. The present study aim is to get a better knowledge of the wrought aluminium components considering both statistical size and gradient effects due to the presence of one or several surface defects of different size.

The investigation is both experimental and numerical. Some plane bending fatigue tests are first carried out on specimens showing the same size and geometry but containing one or several identical surface defects. From the experimental results, a Kitagawa-Takahashi diagram is built showing the difference between the 1-defect and x-defects cases. Then the observed specific size effect is modeled by using Finite Element simulations together with the weakest link concept. Two different approaches are tested, surface and volume-based approaches both reflecting a statistical size effect. The suitability and limitations of these approaches are discussed based on the comparisons with experimental results. The main objectives are:

- Characterization of the statistical size effect

- Description of the crack initiation mechanisms with or without the presence of surface defect

- Modeling the size effect

\section{AA7050-T7451 alloy and experimental procedure}

\subsection{The material}

The material under investigation is the $\mathrm{Al} \mathrm{Zn6CuMgZr} \mathrm{Aluminum}$ alloy, also called AA 7050. In this study, specimens are machined out of a $30 \mathrm{~mm}$ thick sheet. By the local thermomechanical effects induced, machining can change the surface integrity of manufactured parts and therefore change their fatigue strengths. Several studies have shown that in the case of end milled AA7xxx alloys, the geometrical aspect of the surface is the dominant factor on fatigue behaviour [16-18]. Residual stresses as well as the microstructural changes are, in this context, localized to a small thickness layer and will therefore be neglected in the presented study.

The chemical composition of the AA7050-T7451 alloy is given in Table 1. For this range of thickness, the material shows a high recrystallization rate. Areas of consolidation of recrystallized and nonrecrystallized grains can reach a few millimeters of length. Grains have dimensions ranging from 5 to $300 \mu \mathrm{m}$ in rolling and transverse directions, and 5 to $50 \mu \mathrm{m}$ in depth (see Fig. 1). Different types of intermetallic particles are present at the grain boundaries and in the recrystallized grains ( $\mathrm{Mg}_{2} \mathrm{Si}, \mathrm{Al}_{7} \mathrm{Cu}_{2} \mathrm{Fe}, \mathrm{MgZn}_{2}, \mathrm{AlCuZn}$, etc.) (Fig. 2). These particles are brittle and can be at the origin of crack initiation

Table 1

Chemical composition of the AA7050-T7451 alloy, in weight percentage.

\begin{tabular}{cccccccccc}
\hline Element & $\mathrm{Al}$ & $\mathrm{Zn}$ & $\mathrm{Cu}$ & $\mathrm{Mg}$ & $\mathrm{Zr}$ & $\mathrm{Ti}$ & $\mathrm{Si}$ & $\mathrm{Fe}$ & $\mathrm{Mn}$ \\
\hline Weight (\%) & Bal. & 6.027 & 2.221 & 1.847 & 0.102 & 0.039 & 0.038 & 0.095 & 0.01 \\
\hline
\end{tabular}

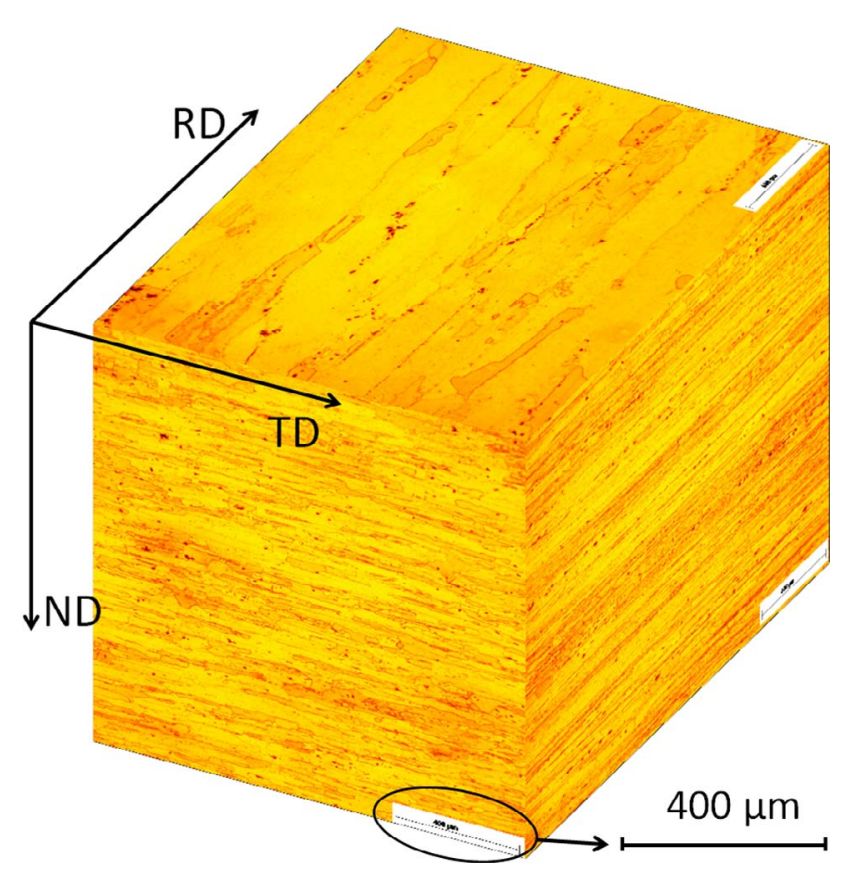

Fig. 1. AA7050-T7451 alloy RD: Rolling Direction, TD: Transverse Direction, ND: Normal Direction.
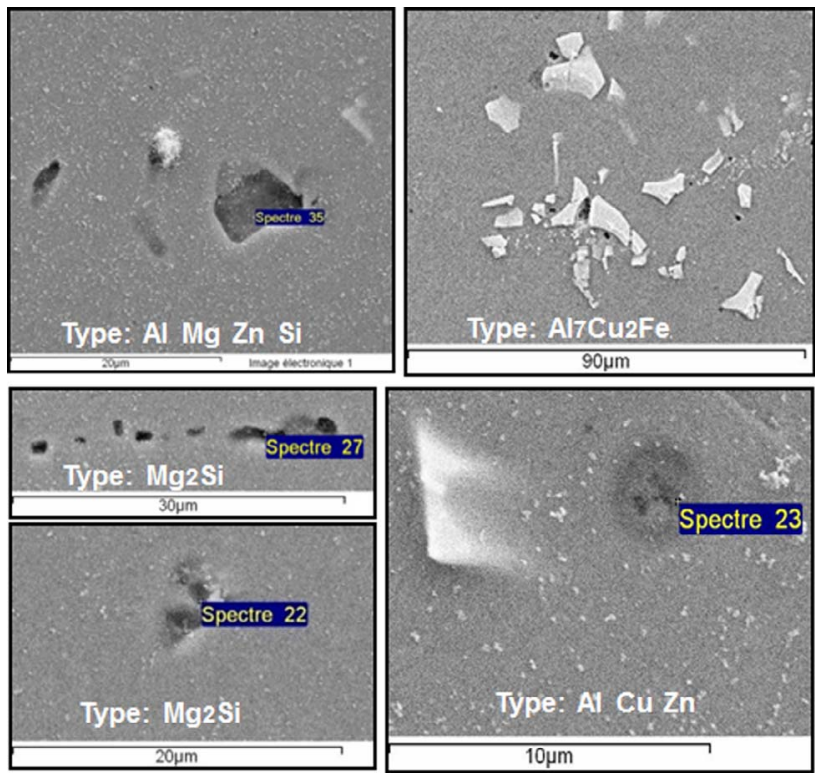

Fig. 2. SEM images of the intermetallic particles observed on the AA7050 alloy sheet.

Table 2

Monotonic properties of the AA7050 alloy.

\begin{tabular}{cccc}
\hline Rolling direction & $\begin{array}{c}\text { Yield stress } \\
(\mathrm{MPa})\end{array}$ & $\begin{array}{c}\text { Ultimate tensile } \\
\text { stress (MPa) }\end{array}$ & $\begin{array}{c}\text { Tensile elongation } \\
(\%)\end{array}$ \\
\hline $0^{\circ}$ & 475 & 635 & 12.3 \\
$45^{\circ}$ & 428 & 496 & 13.9 \\
$90^{\circ}$ & 475 & 538 & 11.9 \\
\hline
\end{tabular}

under fatigue loading $[18,19]$.

Monotonic tensile tests are conducted to determine the mechanical properties of the material at $0^{\circ}, 45^{\circ}$ and $90^{\circ}$ to the rolling direction (Table 2). Geometry of tensile specimen is shown in Fig. 3. The anisotropy is slightly marked and the ductility is limited with a maximum elongation around $13 \%$. In addition, microhardness measurements are 


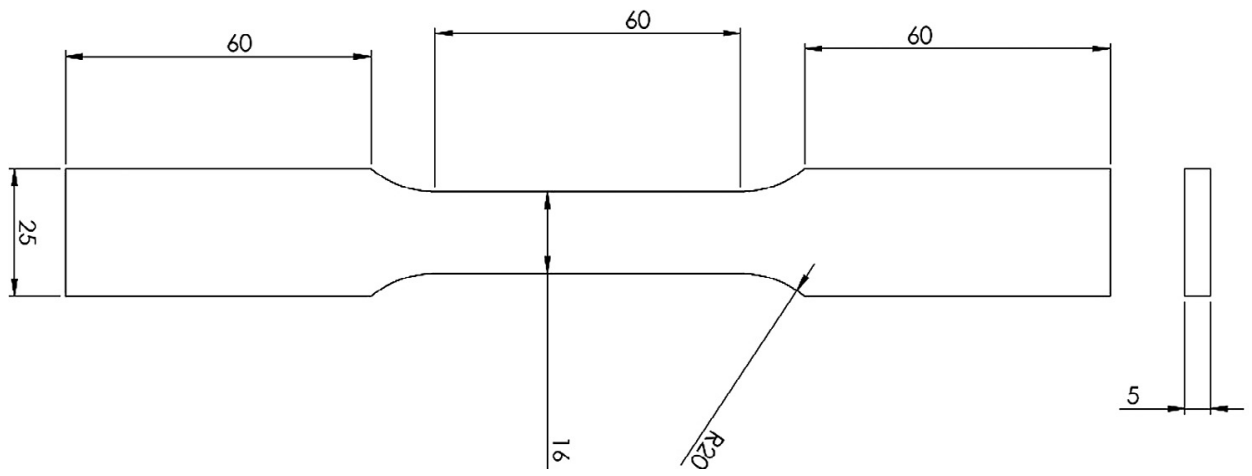

conducted along the sheet depth and show slight variations around 157 $\mathrm{Hv} / 0.5$.

\subsection{Fatigue experimental conditions}

All the fatigue tests are carried out under fully reversed plane bending $(R=-1)$. A specific specimen geometry is developed for this study (Fig. 4). Four chanfrens are machined to avoid corner cracks. Under bending loading, maximum stress is located in the upper (or lower) surface of the gauge length of the specimen. Tests are conducted at a frequency of $75 \mathrm{~Hz}$ with a resonant Rumul Cracktronic type machine at room temperature and ambient air. Fatigue tests are stopped when a frequency drop of $0.7 \mathrm{~Hz}$ is reached (which corresponds to a crack length of $5 \mathrm{~mm}$ or more) or when $2 \times 10^{6}$ cycles are reached. The endurance limit is determined at $2 \times 10^{6}$ cycles using staircase or locati methods. Stress value is decreased and increased by $10 \mathrm{MPa}$ step for staircase and locati method.

Fatigue tests are first carried out according to the staircase method described by Dixon and Mood [20] and according to the standard ISO12107 [21] on 15 polished specimens. The mean fatigue limit with the associated standard deviation are then identified. Specimens with artificial defects of hemispherical shape are tested via the locati technique. The locati technique allows to characterize the fatigue limit for each specimen individually. For each specimen, fatigue test is conducted at a given stress amplitude, assumed to be lower than the fatigue limit. If failure does not occur within the limit cycle number $\left(2 \times 10^{6}\right.$ cycles in our case), the specimen is recycled at a higher stress amplitude [22]. This is repeated until the specimen is fractured after less than $2 \times 10^{6}$ cycles. For a low number of cycles by step, a damage accumulation calculation must be used to estimate the fatigue limit for a given cycle number [23]. In our case, due to the high number of cycles applied on each steps, fatigue limit is directly estimated as the mean stress value between the final loading step leading to failure and the step before. For the locati method, the whole surface of each specimen (including around defect) is observed between each step to check that no crack initiates from the previous step.

Specimens are polished and artificial defects of 6 different sizes are introduced by micro-drilling technique $(\varnothing 60,100,200,400,600$, and $\emptyset 800 \mu \mathrm{m})$. After machining, defects are scanned with a 3D BRUKER type profilometer (see Fig. 6). As it can be seen in Fig. 6, defect depths and diameters are carefully adjusted and controlled.

Using SEM observations of fracture surfaces, no microstructure change is detected due to the machining operation (Figs. 12-14). Moreover, SEM observations and 3D profile measures showed that machined surfaces present a low roughness.

In order to characterize the scale effect, 2-3 specimens per defect size are tested with 1 and 22 defects per specimen (see Table 3 ). In addition, 3 specimens are tested in presence of 44 defects of $\emptyset 400 \mu \mathrm{m}$ (Fig. 5). To avoid interaction effects, the distance between defects is chosen to be more than $2 \mathrm{~mm}$. Fig. 5 shows the distribution of defects on the surface of the gauge length of the specimen. For multiple defect cases, defects are introduced on the specimen along 2 or 3 straight lines with the specimens length direction (i.e. Fig. 5b-d). The position of the defects is shifted so as to have a single defect per section along the gauge length of the specimen. In order to characterize the scatter of the fatigue limit, 3 staircases are conducted on: polished specimens, polished specimens with a defect of $\emptyset 400 \mu \mathrm{m}$ and polished specimens with 22 defects of $\varnothing 400 \mu \mathrm{m}$. Specimens that survived in the staircase procedure were retested at a higher load in order to identify the Wöhler curve shape (polished specimens) or to determine fatigue limit via locati method ( $\varnothing 400 \mu \mathrm{m}$ defect specimens).

\subsection{Fatigue test results and fatigue damage mechanisms}

All the fatigue test results are gathered in a Kitagawa-Takahashi diagram shown in Fig. 7. Fatigue data are also shown in Tables 3-5.

The errors bars in Fig. 7 show, depending on the method used, the fatigue strength range obtained via the locati or the standard deviation estimated via the staircase.

For the polished specimens, the staircase method allowed to identify a mean fatigue limit of $174 \mathrm{MPa}$ with a low standard deviation of $5.3 \mathrm{MPa}$ (Fig. 8). Fig. 8 shows a plateau over $3 \times 10^{5}$ cycles which corresponds to the well known fatigue limit observed in the HCF domain between $3 \times 10^{5}$ and $10^{7}$ cycles. This result is in agreement with

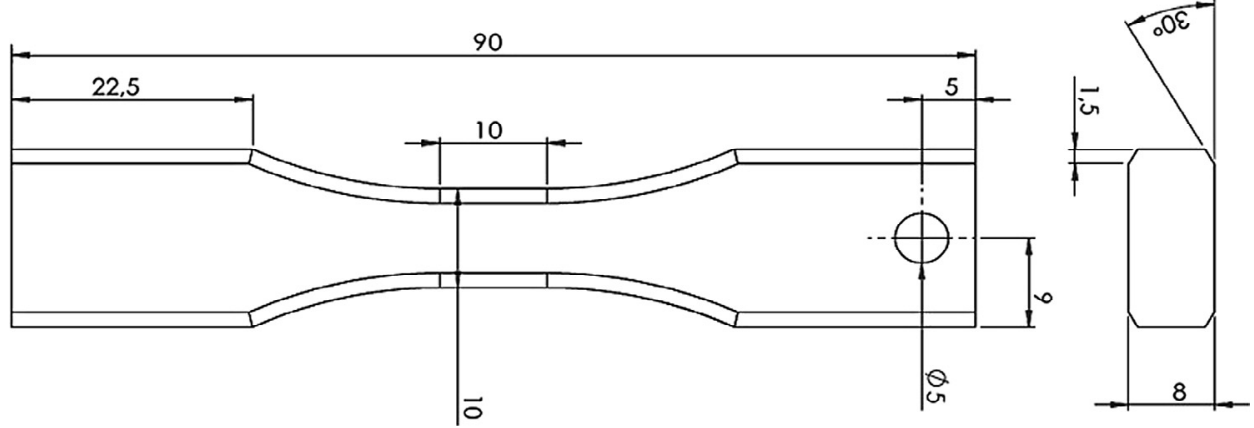

Fig. 4. Geometry of plane bending specimen showing four chanfrens. 

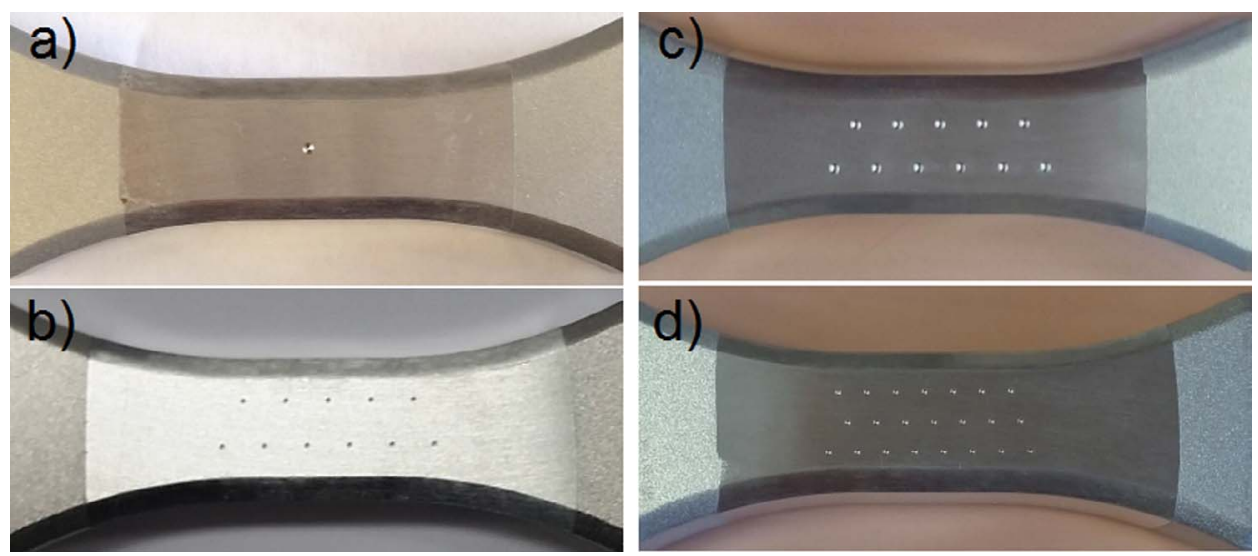

Fig. 5. Plane bending specimens with (a) 1 defect of $\emptyset 800 \mu \mathrm{m}$, (b) 22 defects of $\emptyset 400 \mu \mathrm{m}$, (c) 22 defects of $\emptyset 600 \mu \mathrm{m}$ and (d) 44 defects of $\emptyset 400 \mu \mathrm{m}$.
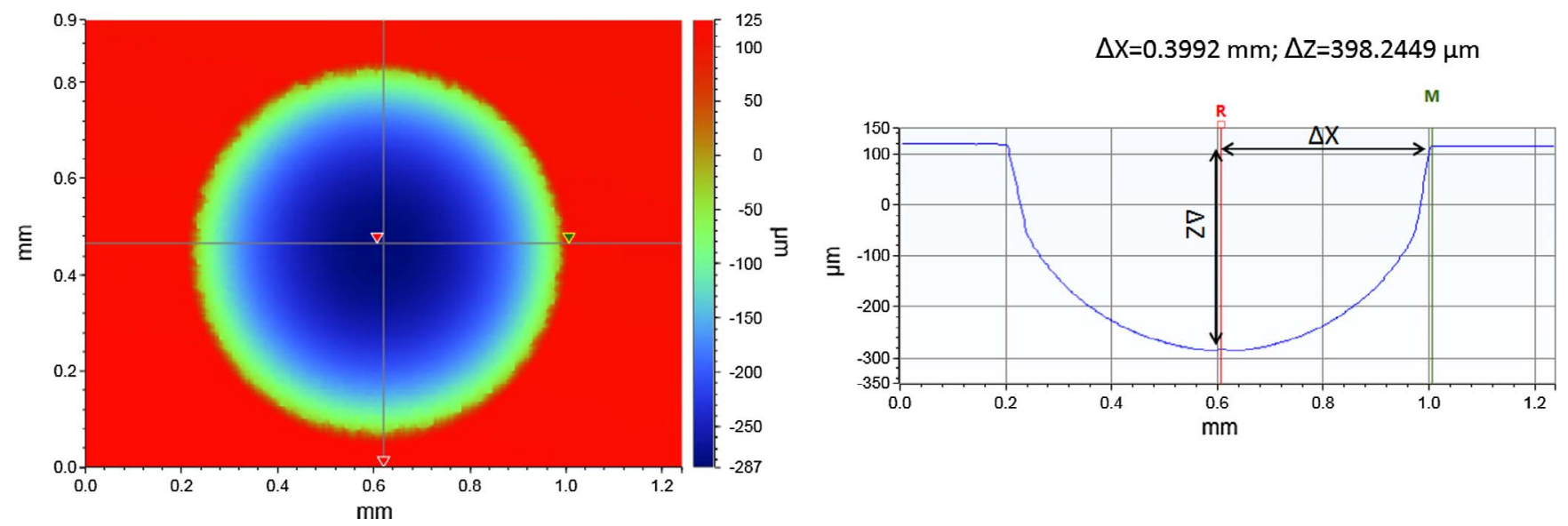

Fig. 6. 3D surface scan of a $\emptyset 800 \mu \mathrm{m}$ defect and corresponding 2D profile.

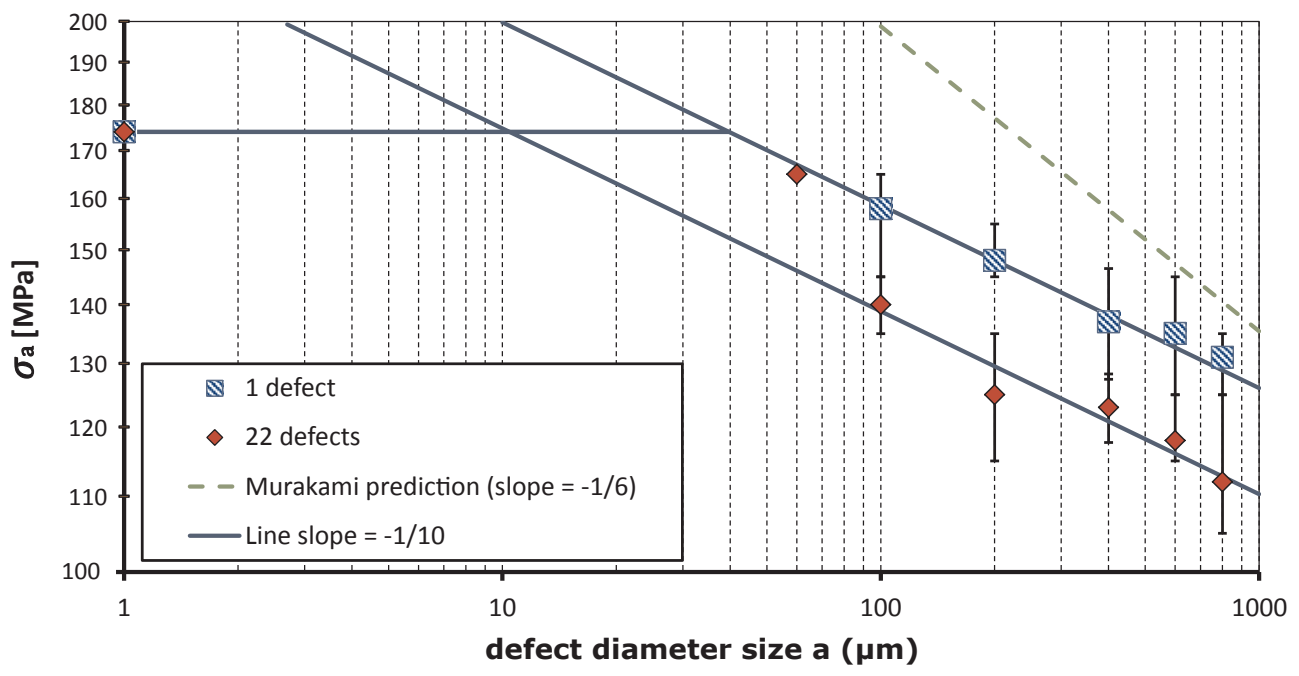

Fig. 7. Kitagawa-Takahashi diagram, AA7050 alloy: experimental results for different defect size and number.

other results in the literature that show the presence of a plateau for this type of material $[24,25]$. It assumes that this asymptote on the case of specimen without a defect is also present on the case of specimen with a defect since the used material is the same.

In presence of a single defect, fatigue limit decreases progressively with the increase of the defect size. This behavior is known as the Kitagawa effect [26] (Fig. 7).

As shown on the Kitagawa-Takahashi diagram (Fig. 7) the number of introduced defects affect the fatigue response. A drop of $20 \mathrm{MPa}$ is observed when the number of defects is multiplied by 22 . This decrease can be explained by a scale effect. When increasing the number of defects, the highly stressed volume increases and the probability of finding an heterogeneity (i.e particle) or an unfavorably oriented grain increases. Hence, crack initiation is more likely to occur at a lower stress value than in the case with a single defect.

As shown in Fig. 7, the slope of decrease in fatigue limit is not dependent on the defect number. In case of 1 and 22 defects, the slope is around $(-1 / 10)$. This is quite different from the $(-1 / 6)$ slope given by the Murakami criterion [27] (Fig. 7). Let us recall that the Murakami criterion allows to predict the fatigue strength of a specimen based on 
Table 3

Test history for locati tested specimens.

\begin{tabular}{|c|c|c|c|c|c|c|}
\hline \multirow{2}{*}{$\begin{array}{l}\text { Specimen } \\
\text { name }\end{array}$} & \multicolumn{2}{|c|}{ Artificial defect } & \multirow{2}{*}{$\begin{array}{l}\text { Loading at } \\
\text { failure } \\
(\mathrm{MPa}) \\
\sigma_{a} \\
(\mathrm{R}=-1)\end{array}$} & \multirow{2}{*}{$\begin{array}{l}\text { Step } \\
\text { number }\end{array}$} & \multirow{2}{*}{$\begin{array}{l}N_{f} \\
\left(\times 10^{5}\right)\end{array}$} & \multirow{2}{*}{$\begin{array}{l}\text { Initiation } \\
\text { from } \\
\text { artificial } \\
\text { defect } \\
\text { Yes/No }\end{array}$} \\
\hline & $\begin{array}{l}\text { Diameter } \\
\text { in } \mu \mathrm{m}\end{array}$ & $\begin{array}{l}\text { Defects } \\
\text { number }\end{array}$ & & & & \\
\hline D60-22-1 & 60 & 22 & 170 & 4 & 7.72 & $\mathrm{Y}$ \\
\hline D60-22-2 & 60 & 22 & 170 & 3 & 2.86 & $\mathrm{Y}$ \\
\hline D100-1-1 & 100 & 1 & 170 & 4 & 7.59 & $\mathrm{~N}$ \\
\hline D100-1-2 & 100 & 1 & 170 & 3 & 4.66 & $\mathrm{~N}^{\mathrm{a}}$ \\
\hline D100-1-3 & 100 & 1 & 150 & 2 & 5.65 & $\mathrm{Y}^{\mathrm{a}}$ \\
\hline D100-22-1 & 100 & 22 & 150 & 4 & 3.7 & $\mathrm{Y}$ \\
\hline D100-22-2 & 100 & 22 & 140 & 2 & 14.5 & $\mathrm{Y}$ \\
\hline D200-1-1 & 200 & 1 & 160 & 3 & 11.26 & $\mathrm{Y}$ \\
\hline D200-1-2 & 200 & 1 & 150 & 2 & 7.81 & $\mathrm{Y}$ \\
\hline D200-1-3 & 200 & 1 & 150 & 2 & 11.11 & $\mathrm{Y}^{\mathrm{a}}$ \\
\hline D200-22-1 & 200 & 22 & 130 & 4 & 4.48 & $\mathrm{Y}$ \\
\hline D200-22-2 & 200 & 22 & 140 & 4 & 16.39 & $\mathrm{Y}$ \\
\hline D200-22-3 & 200 & 22 & 120 & 2 & 15.93 & $\mathrm{Y}$ \\
\hline D400-1-1 ${ }^{\mathrm{b}}$ & 400 & 1 & 150 & 3 & 1.33 & $\mathrm{Y}$ \\
\hline D400-1-5 & 400 & 1 & 140 & 3 & 5.4 & $\mathrm{Y}^{\mathrm{a}}$ \\
\hline$D 400-1-6^{b}$ & 400 & 1 & 150 & 3 & 1.97 & $\mathrm{Y}$ \\
\hline D400-1-8 & 400 & 1 & 140 & 2 & 5.31 & $\mathrm{Y}^{\mathrm{a}}$ \\
\hline D400-1-9 & 400 & 1 & 150 & 2 & 2.76 & $\mathrm{Y}$ \\
\hline D $400-22-3^{b}$ & 400 & 22 & 130 & 2 & 3.67 & $\mathrm{Y}$ \\
\hline D400-22- $6^{\mathrm{b}}$ & 400 & 22 & 120 & 2 & 9.86 & $\mathrm{Y}^{\mathrm{a}}$ \\
\hline D400-22-7 & 400 & 22 & 130 & 2 & 7.55 & $\mathrm{Y}^{\mathrm{a}}$ \\
\hline D400-22-9 & 400 & 22 & 130 & 2 & 8.94 & $\mathrm{Y}$ \\
\hline D400-44-1 & 400 & 44 & 120 & 3 & 7.88 & $\mathrm{Y}$ \\
\hline D400-44-2 & 400 & 44 & 120 & 3 & 4.93 & $\mathrm{Y}$ \\
\hline D400-44-3 & 400 & 44 & 120 & 2 & 18.33 & $\mathrm{Y}^{\mathrm{a}}$ \\
\hline D600-1-1 & 600 & 1 & 150 & 6 & 6.67 & $\mathrm{Y}$ \\
\hline D600-1-2 & 600 & 1 & 130 & 2 & 12.28 & $\mathrm{Y}$ \\
\hline D600-1-3 & 600 & 1 & 140 & 3 & 10.63 & $\mathrm{Y}$ \\
\hline D600-22-1 & 600 & 22 & 130 & 2 & 16.48 & $\mathrm{Y}$ \\
\hline D600-22-2 & 600 & 22 & 120 & 3 & 10.88 & $\mathrm{Y}^{\mathrm{a}}$ \\
\hline D600-22-3 & 600 & 22 & 120 & 3 & 17.69 & $\mathrm{Y}^{\mathrm{a}}$ \\
\hline D800-1-1 & 800 & 1 & 140 & 5 & 3.11 & $\mathrm{Y}$ \\
\hline D800-1-2 & 800 & 1 & 130 & 4 & 13.69 & $\mathrm{Y}$ \\
\hline D800-1-3 & 800 & 1 & 140 & 4 & 2.89 & $\mathrm{Y}^{\mathrm{a}}$ \\
\hline D800-22-1 & 800 & 22 & 110 & 3 & 19.89 & $\mathrm{Y}^{\mathrm{a}}$ \\
\hline D800-22-2 & 800 & 22 & 130 & 6 & 2.9 & $\mathrm{Y}^{\mathrm{a}}$ \\
\hline D800-22-3 & 800 & 22 & 110 & 2 & 16.6 & $\mathrm{Y}^{\mathrm{a}}$ \\
\hline
\end{tabular}

\footnotetext{
${ }^{a}$ Intermetallic particle at fracture site.
}

b Retested after staircase. initiation starts from a single artificial defect randomly located on the specimen surface (Fig. 9).

For polished specimens, SEM observations showed the presence of intermetallic particles at the crack initiation site of several specimens (66\%) (Fig. 10). These particles are identified via energy dispersive $\mathrm{X}$ ray spectroscopy (EDS) analysis as $\mathrm{Mg}_{2} \mathrm{Si}$ and $\mathrm{Al}_{7} \mathrm{Cu}_{2} \mathrm{Fe}$. For some specimens, SEM observations showed no defects at the crack initiation site. However, in some cases, EDS analysis showed the presence of Mg elements with the $\mathrm{Al}$ and $\mathrm{Zn}$ elements at the crack initiation site (Fig. 10). As shown in the literature, the presence of these elements may indicate the presence of $\mathrm{MgZn}_{2}$ precipitates at a nanoscale [28].

For the case of specimens containing artificial defects below the size of $100 \mu \mathrm{m}$, cracks do not necessarily initiate from the artificial defect (see Fig. 11). Above this size, the crack initiation is always located at an artificial defect (see Figs. 12-14).

In the case of 1 and 22 defects, around 50\% of initiation occurs from particles. These particles can be observed at the initiation site along the artificial defect for example close to the corner defect (Fig. 13) or in the middle of the defect (Fig. 14). In the case of the absence of particles, crack initiates at the upper side of the hemispherical defect but without any preferential side (same case as Fig. 12)). This location corresponds to the maximum stressed area (in terms of principal or Von-Mises equivalent stress) due to the applied bending loading. Stress distribution around the defect is shown further in this paper (see Fig. 17).

The fatigue limit decrease with the increase of defects number cannot be explained only by the presence of intermetallic particles because the percentage of initiation site with particle is the same for specimen with 1 and 22 defects. Other factors can have an effect on the crack initiation localisation. Grain size at the defect's location, orientation as well as their vicinity are possible causes for crack initiation. The effects of grain size and orientation on fatigue behaviour is an actual and an open question that is discussed in several papers $[29,30]$.

\section{A probabilistic fatigue criterion to account for the size effect}

After the previous comprehensive experimental investigation of the size effect due to surface defects, it is now proposed to describe a modelling strategy accounting for both the change in size of the loaded volume and the stress gradient.

\subsection{Probabilistic framework}

This section is devoted to the modelling of the crack initiation damage mechanism in a polycrystalline aggregate containing geometric defects.

As a general rule most fatigue criteria can be defined by an equivalent mechanical quantity (i.e. stress, strain, energy, etc.), which is compared to a threshold quantity, for a given number of cycles. Crack initiation is subsequently predicted if the equivalent quantity is greater than or equal to the threshold quantity. In the following, for convenience, these will be referred to stress quantities. Hence, the condition for crack initiation is defined by:

$\sigma_{e q} \geqslant \sigma_{t h}$

Note that in this section, the maximum normal stress amplitude is considered as responsible for crack initiation. Even though the maximum normal stress criterion is not well suited to model the fatigue behaviour of ductile material, this criterion is chosen for its simplicity and is used below to explain the proposed methodology.

In order to take into account the inherent stochastic nature of the fatigue phenomenon it is proposed, as part of the modelling framework, to use a two parameter Weibull distribution $[31,6]$ to describe the threshold stress $\sigma_{t h}$.

This choice then makes it possible to define the probability of crack initiation. Eq. (3) shows the probability density function used to define the threshold stress. 
Table 4

Test history for staircase tested specimens.

\begin{tabular}{|c|c|c|c|c|c|c|c|c|c|c|c|c|c|c|c|c|}
\hline \multirow[t]{2}{*}{ Surface state } & \multirow[t]{2}{*}{ Stress $[\mathrm{MPa}]$} & \multicolumn{15}{|c|}{ Specimen $N^{\circ}$} \\
\hline & & 1 & 2 & 3 & 4 & 5 & 6 & 7 & 8 & 9 & 10 & 11 & 12 & 13 & 14 & 15 \\
\hline & 180 & & & $\mathrm{X}^{\mathrm{a}}$ & & $\mathrm{X}^{\mathrm{b}}$ & & $\mathrm{X}$ & & $\mathrm{X}$ & & & & $\mathrm{X}^{\mathrm{b}}$ & & $\mathrm{X}$ \\
\hline \multirow[t]{3}{*}{ Polished } & 170 & & $\mathrm{O}$ & & $\mathrm{O}^{\mathrm{b}}$ & & $\mathrm{O}$ & & $\mathrm{O}^{\mathrm{b}}$ & & $\mathrm{X}^{\mathrm{a}}$ & & $\mathrm{O}^{\mathrm{a}}$ & & $\mathrm{O}$ & \\
\hline & 160 & $\mathrm{O}^{\mathrm{a}}$ & & & & & & & & & & $\mathrm{O}^{\mathrm{a}}$ & & & & \\
\hline & 150 & & $\mathrm{X}$ & & & & & & & & $\mathrm{X}^{\mathrm{a}}$ & & & & & \\
\hline$\varnothing 400$ & 140 & $\mathrm{O}$ & & $\mathrm{X}^{\mathrm{a}}$ & & & & $\mathrm{X}$ & & $\mathrm{O}$ & & & & & & \\
\hline \multirow[t]{3}{*}{1 defect } & 130 & & & & $\mathrm{X}^{\mathrm{a}}$ & & $\mathrm{O}$ & & $\mathrm{O}^{\mathrm{a}}$ & & & & & & & \\
\hline & 120 & & & & & $\mathrm{O}^{\mathrm{a}}$ & & & & & & & & & & \\
\hline & 130 & & $\mathrm{X}$ & & $\mathrm{X}$ & & & & $\mathrm{X}$ & & $\mathrm{X}^{\mathrm{a}}$ & & & & & \\
\hline$\varnothing 400$ & 120 & $\mathrm{O}$ & & $\mathrm{O}^{\mathrm{a}}$ & & $\mathrm{X}^{\mathrm{a}}$ & & $\mathrm{O}$ & & $\mathrm{O}^{\mathrm{a}}$ & & & & & & \\
\hline 22 defects & 110 & & & & & & $\mathrm{O}^{\mathrm{a}}$ & & & & & & & & & \\
\hline
\end{tabular}

${ }^{\text {a }}$ Particle at fracture site.

${ }^{\mathrm{b}} \mathrm{MgZn}_{2}$ traces found at fracture site.

Table 5

Average fatigue limit and associated standard deviation for tested surface states.

\begin{tabular}{cccc}
\hline Surface state & $\begin{array}{c}\text { Average fatigue } \\
\text { limit } \overline{\sigma_{D}}\end{array}$ & $\begin{array}{c}\text { Standard deviation } \\
\overline{\overline{\sigma_{D}}}\end{array}$ & Covariance $\overline{\overline{\sigma_{D}}} / \overline{\sigma_{D}}$ \\
\hline Polished $^{\mathrm{a}}$ & 174 & 5.3 & 0.03 \\
$\varnothing 4001$ defect $^{\mathrm{a}}$ & 137 & 9.5 & 0.069 \\
$\varnothing 40022$ defects $^{\mathrm{a}}$ & 123 & 5.3 & 0.043 \\
$\varnothing 40044$ defects & 115 & $\mathrm{X}$ & $\mathrm{X}$ \\
\hline
\end{tabular}

${ }^{\text {a }}$ Results based on staircase method described by Dixon and Mood [20].

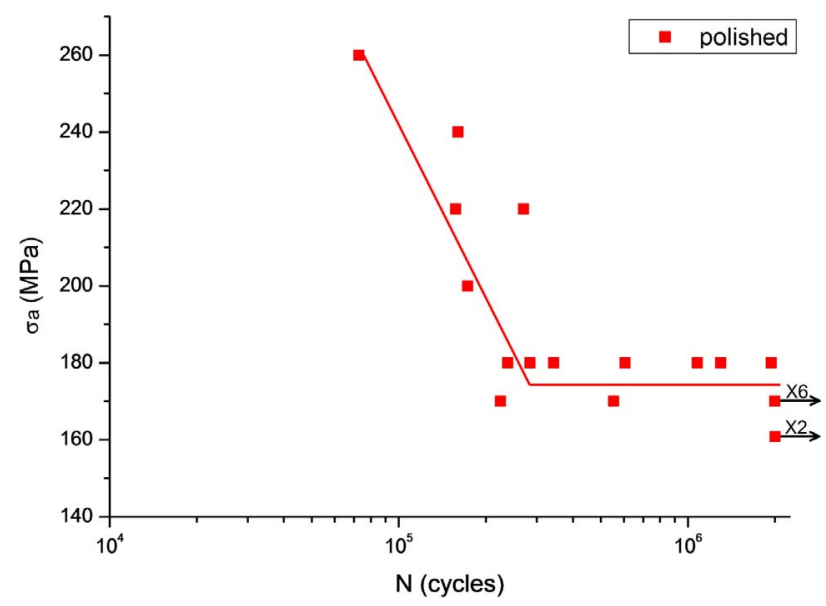

Fig. 8. S-N curve for polished specimens, AA7050 alloy.

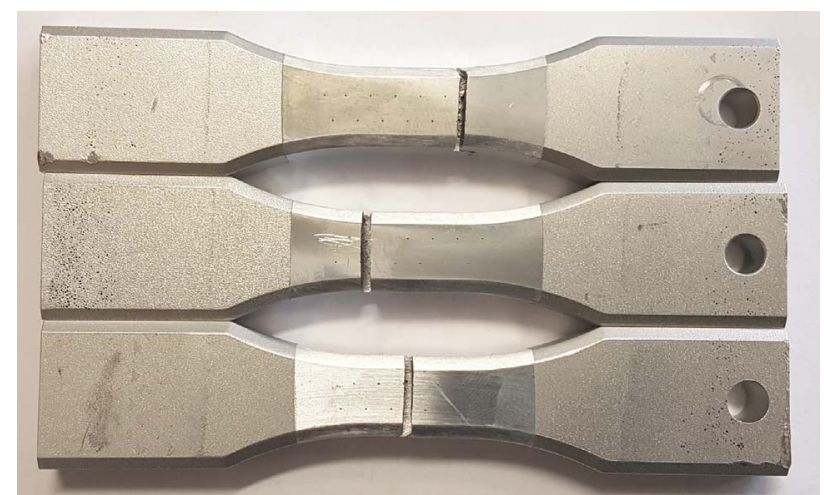

Fig. 9. Iniation site randomly located on 3 specimens containing 22 defects of $\emptyset 200 \mu \mathrm{m}$ (specimens D200-22-1, D200-22-2 and D200-22-3). $f_{0}\left(\sigma_{t h}\right)=\frac{m}{\sigma_{0}}\left(\frac{\sigma_{t h}}{\sigma_{0}}\right)^{m-1} \exp \left\{-\left(\frac{\sigma_{t h}}{\sigma_{0}}\right)^{m}\right\}$

where $\sigma_{0}$ is the scale parameter and $m$ is the shape parameter (or the Weibull exponent) used to reflect the scatter associated with the threshold stress and hence the fatigue limit.

The probability of microcrack initiation corresponds to the probability of finding a threshold stress $\sigma_{t h}$ that is less than the applied equivalent stress $\sigma_{e q}$. This can be expressed as:

$P_{F_{0}}=\left(\sigma_{t h}<\sigma_{e q}\right)=\int_{0}^{\sigma_{e q}} f_{0}\left(\sigma_{t h}\right) d \sigma_{t h}$

Using the simple equation of Weibull's distribution function, the integration allows to express the failure probability as follows:

$P_{F_{0}}=1-\exp \left[-\left(\frac{\sigma_{e q}}{\sigma_{0}}\right)^{m}\right]$

To obtain the probability of crack initiation for the complete structure $P_{F}$, the weakest link theory is used [5]. The probability of survival of the structure $\left(1-P_{F}\right)$ is defined as the product of the survival probabilities of each elementary volume or surface. In this work it will be firstly assumed that crack initiation is essentially a surface phenomenon, where the quantity $S_{0}$ corresponds to a reference surface area and $S_{\Omega}$ is the total surface area of a specimen.

$1-P_{F}=\prod_{S_{\Omega}}\left(1-P_{F_{0}}\right)$

Hence the probability of survival of the complete structure is given by:

$P_{F}=1-\exp \left[-\frac{1}{S_{0}} \int_{S_{\Omega}}\left(\frac{\sigma_{e q}}{\sigma_{0}}\right)^{m} d S\right]$

Introducing the surface stress heterogeneity factor on the component surface $H_{m s}$ [13]:

$H_{m s}=\frac{1}{S_{\Omega}} \int_{S_{\Omega}}\left(\frac{\sigma_{e q}}{\sigma_{\max }}\right)^{m} d S$

with $\sigma_{\max }$ the maximum equivalent stress on the component surface:

$\sigma_{\max }=\max _{S_{\Omega}}\left(\sigma_{e q}\right)$

The expression for the failure probability of the total structure becomes:

$P_{F}=1-\exp \left[-\frac{S_{\Omega}}{S_{0}} H_{m s}\left(\frac{\sigma_{\max }}{\sigma_{0}}\right)^{m}\right]$

In order to simplify the expression and to make a link with the high 


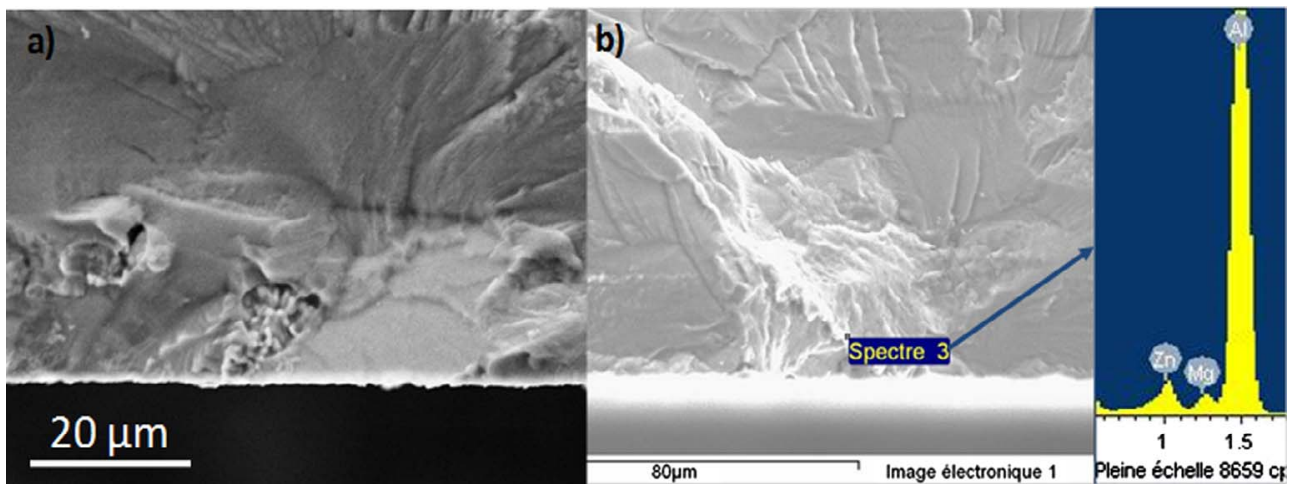

Fig. 10. SEM observations on polished specimens: (a) particles at the crack initiation and (b) $\mathrm{MgZn}_{2}$ traces found at fracture site.
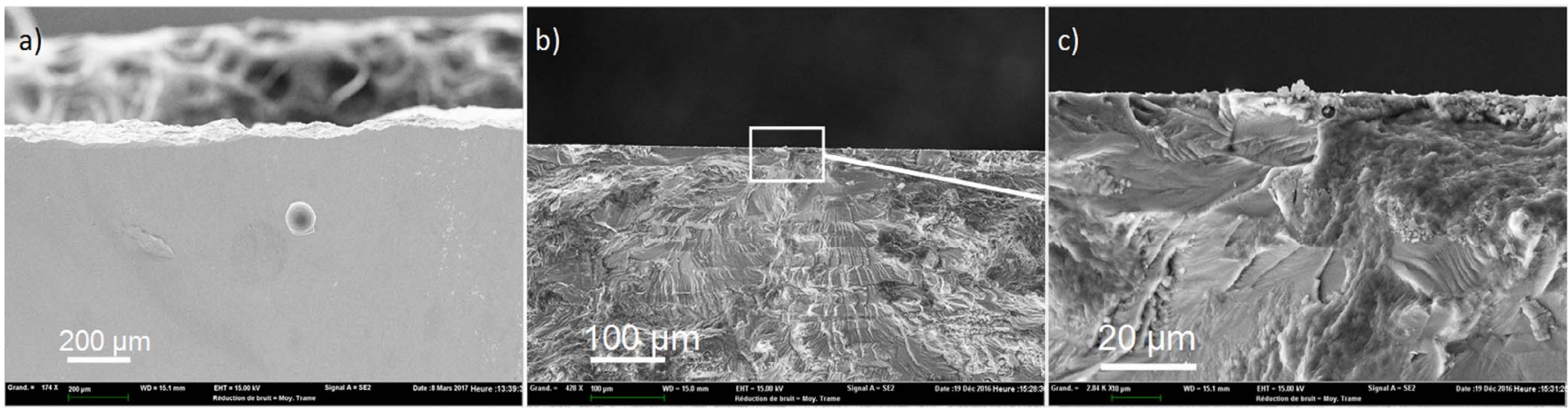

Fig. 11. Specimen with a single defect (D100-1-1): (a) specimens fracture occurs away from the defect, (b) and (c) crack initiation site.
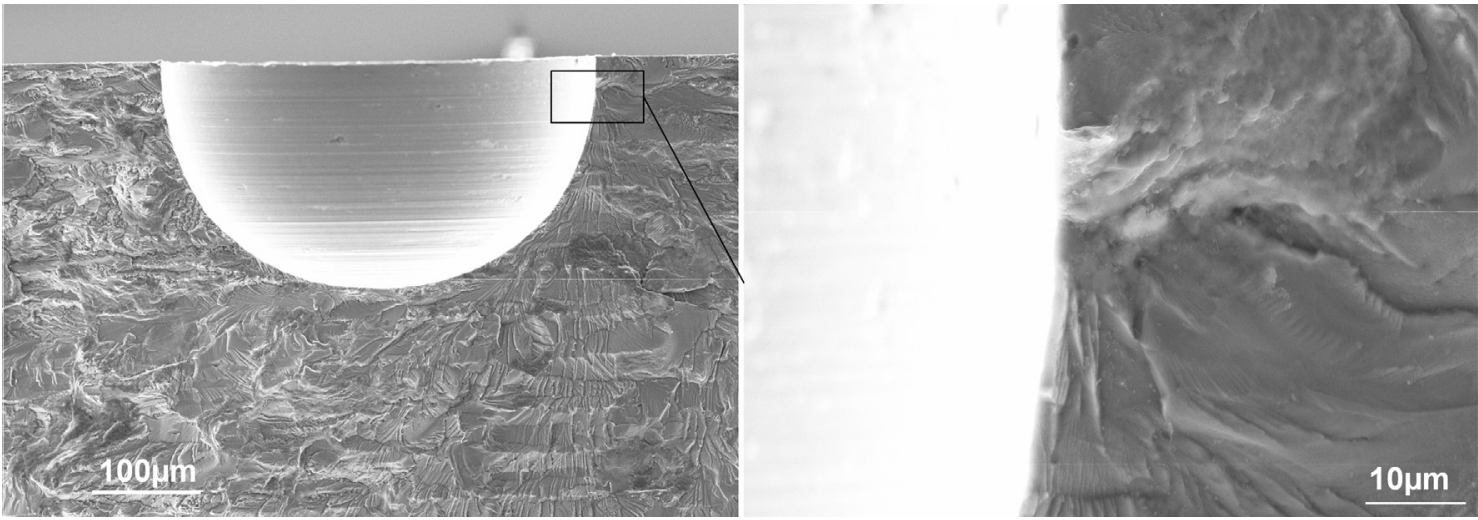

Fig. 12. Crack initiation site from a defect without a particle (specimen D400-44-1).

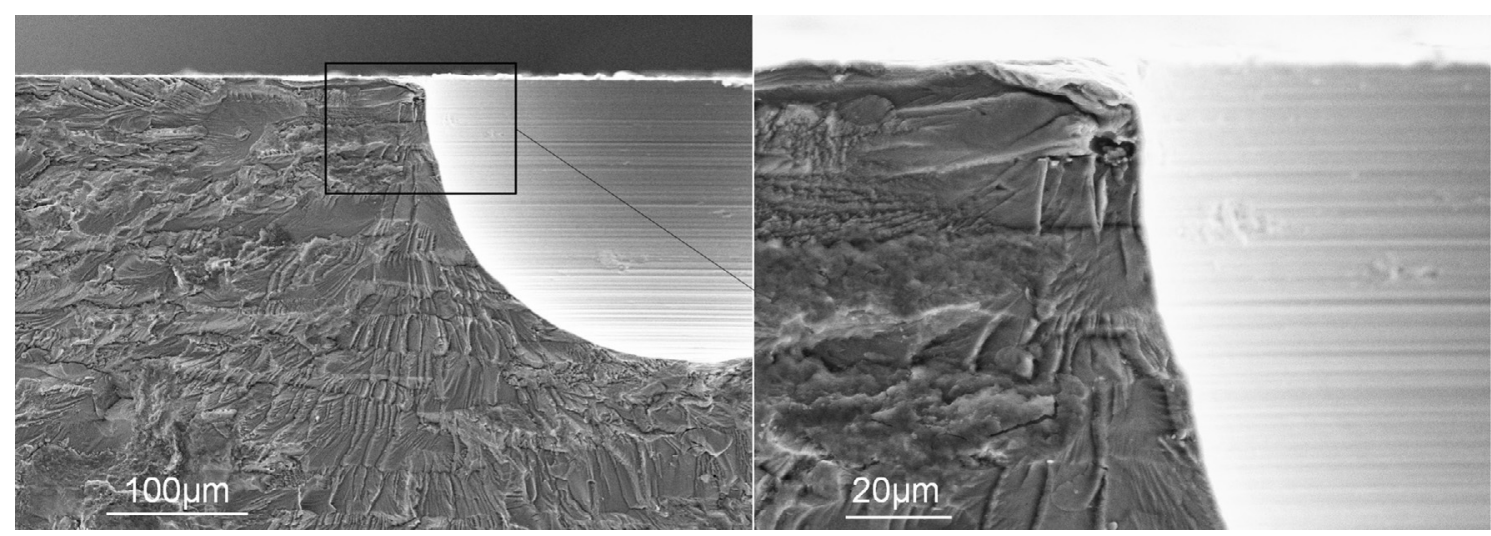

Fig. 13. Crack initiation site from the corner defect with a particle (specimen D400-22-7) 

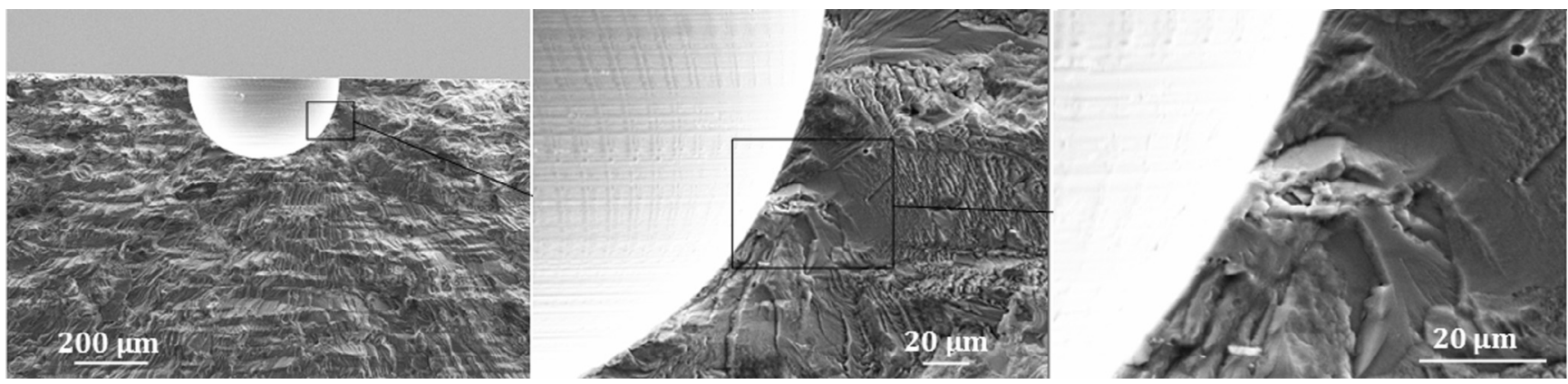

Fig. 14. Crack initiation site from the middle of the defect with a particle (specimen D400-1-5).

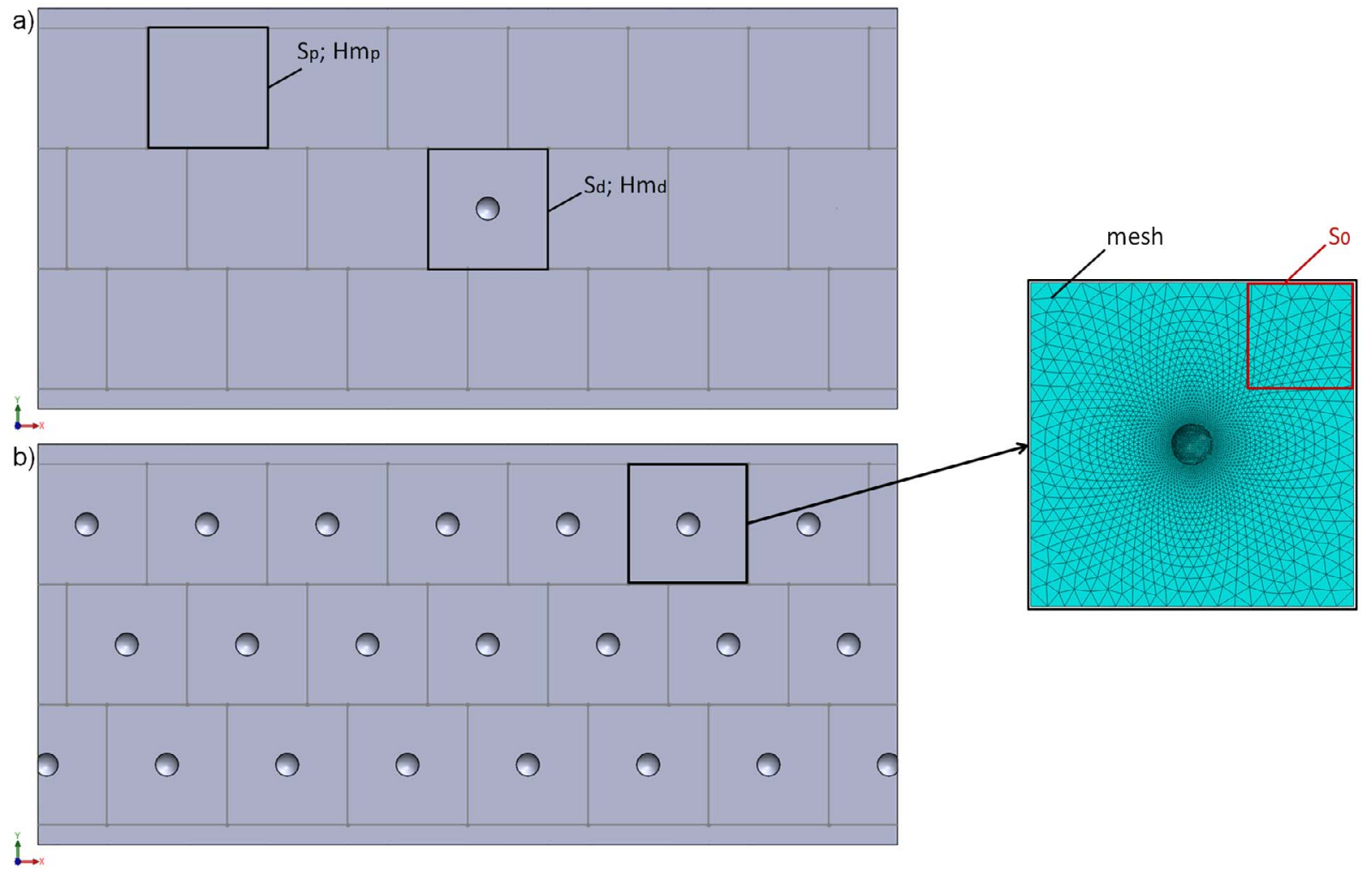

Fig. 15. The two different cells defined Sp and Sd, for fatigue analysis purpose (a) 1 surface defect; (b) 44 surface defects.

cycle fatigue limit, the macroscopic fatigue limit $\sigma_{a}$ can be expressed via the following expression:

$\sigma_{a}=\frac{\sigma_{0}}{K_{t_{\max }}}\left[\frac{S_{0}}{S_{\Omega}} \frac{\ln \left(\frac{1}{1-P_{F}}\right)}{H_{m s}}\right]^{1 / m}$

where $K_{t_{\max }}$ is the maximal equivalent stress concentration factor which correspond to the maximal equivalent stress divided by the nominal applied stress.

$K_{t_{\max }}=\frac{\sigma_{\max }}{\sigma_{\text {applied }}}$

In the case of polished specimen and a simple uniaxial loading, the surface stress heterogeneity factor $H_{m s}$ could be easily obtained by an analytical calculation [13]. In our study, the surface stress field due to hemispherical defect is more complex and numerical finite element simulation must be conducted to assess this quantity.

\subsection{Finite element simulations to account for artificial defect}

The surface stress heterogeneity factor $H_{m s}$ is used to characterize the heterogeneity of the surface stress field on the entire component. To simplify the $H_{m s}$ calculation and to avoid simulating the entire component, the total surface is divided in different cells. An example of the choice of the cell size and its position regarding surface defects is shown in Fig. 15. The cell surface containing a defect is noted $S_{d}$ and the polished surface cell without a defect is noted $S_{p}$.

The cell size must be adapted to the size and to the number of defect introduced in the specimen. For defects higher than $\emptyset 500 \mu \mathrm{m}$, cell size is chosen as $3.1 \mathrm{~mm} \times 3.1 \mathrm{~mm}$. For smaller defects, cell size is chosen as $2.1 \mathrm{~mm} \times 2.1 \mathrm{~mm}$ that allows to introduce 44 cells with defects of $\emptyset 400 \mu \mathrm{m}$ in the total specimen surface.

For a specimen containing $n$ defects, the proposed notation allows to obtain a simple expression of $H_{m s}$ based on the surface stress heterogeneity factor of cells with defects $H_{m s_{d}}$ and without defects $H_{m s_{p}}$.

$H_{m s}=\frac{1}{S_{\Omega}}\left[n S_{d} H_{m s_{d}}+\frac{S_{\Omega}-n S_{d}}{K_{t_{\max }^{m}}^{m}} H_{m s_{p}}\right]$

with $H_{m s d}$ the surface stress heterogeneity factor of a cell containing a defect: 
$H_{m s d}=\frac{1}{S_{d}} \int_{S_{d}}\left(\frac{\sigma_{e q}}{\sigma_{\max }}\right)^{m} d S$

and $H_{m s_{p}}$ the surface stress heterogeneity factor of a cell without any defect, equal to one in our case:

$H_{m s_{p}}=1$

To calculate the surface stress heterogeneity of defect cells, a finite element simulation is performed on a cube containing a hemispherical defect on its upper surface (see Fig. 16). Calculation is conducted in order to assess the stress in each element on the surface. Elements are tetrahedral with reduced integration and convergence of calculation results is verified with the chosen size of elements. The material is supposed to be homogeneous and an elastic behaviour is used. The potential residual stresses are also neglected. The boundary conditions are as follows:

- Displacement $\mathrm{Ux}=0$ along the plane $X=0$ (surface A).

- Displacement $\mathrm{Uy}=0$ along the line $X=0, Y=0$.

- Displacement $\mathrm{Uz}=0$ at the point $X=0, Y=0, Z=0$.

A bending pressure function representative of experimental bending loading is applied along the surface B (Fig. 16).

The maximal stress concentration factor $K_{t_{\max }}$ is the same for the different defects size and is equal to 2.2. Due to the bending loading, the maximum principal stress is not localized at the bottom of the hemispherical defect but close to the surface (Fig. 17).

Fig. 18 compares the maximal principal stress gradient in depth for different defect size and from the bottom of the defect. Fig. 18 shows that the maximal stress value is the same for the different defect size and that the gradient associated to the bending loading (presented for the polished surface state without a defect) is negligible compared to the gradient generated by the defect.

\subsection{The identification procedure}

The proposed criterion is a 2 parameters model with the shape parameter $m$ and the scale parameter $\sigma_{0}$ to be identified. To get them, results of staircase obtained on specimens with a single defect of $\emptyset 400 \mu \mathrm{m}$ is used as reference. For this surface state, the average fatigue limit is $\overline{\sigma_{a}}=137 \mathrm{MPa}$ with a standard deviation $\overline{\sigma_{a}}$ of $9.5 \mathrm{MPa}$.

The shape parameter $m$ associated to the scatter can be calculated from the standard deviation and the average fatigue strength using the following relationship (16):

$$
\frac{\overline{\overline{\sigma_{a}}}}{\overline{\sigma_{a}}}=\frac{\sqrt{\Gamma\left(1+\frac{2}{m}\right)-\Gamma^{2}\left(1+\frac{1}{m}\right)}}{\Gamma\left(1+\frac{1}{m}\right)}
$$

with $\Gamma$ the Gamma function (or Euler function) given by:

$\Gamma(t)=\int_{0}^{\infty} x^{t-1} e^{-x} d x$

Using Eqs. (16) and (17), $m$ is found to be 17.

The scale parameter $\sigma_{0}$ is then identified using Eq. (11) and the finite element simulation results $H_{m s}$ and $K_{t_{\max }}$ calculated for a specimen containing a hemispherical defect of $\varnothing 400 \mu \mathrm{m}$. For a $S_{0}$ of $1 \mathrm{~mm}^{2}, \sigma_{0}$ is equal to $240 \mathrm{MPa}$.

\subsection{Predictions using a surface approach}

The surface stress heterogeneity factor can be calculated for different defect sizes and numbers. Fig. 19 shows that $H_{m s}^{1 / m}$ increases with the defect size as well as the defect number due to the fact that the increase of defect size or number leads to the increase of the highly stressed area. Stress gradient in depth also depends on defect size as shown in Figs. 17 and 18.

Eqs. (11) and (13) are used to predict the fatigue limit in the presence of 1 and 22 defects. A comparison of experimental results and predictions is shown in Fig. 20. Predictions are in good agreement with experimental results. The drop of the fatigue limit with the defect size increase is successfully predicted. Also, scale effect is correctly reflected. In addition, fatigue limit for the polished specimen without defect is correctly predicted (see Fig. 20). However, for defects lower than $\varnothing 100 \mu \mathrm{m}$, predictions are conservative and error reaches $15 \%$ (case of $\emptyset 60 \mu \mathrm{m}$ ). The physical asymptote presented experimentally at this defect size is not well described by the surface approach.

For the $\varnothing 400 \mu \mathrm{m}$ defect, the predicted fatigue limit for different number of defects is compared to experimental results (Fig. 21). Predictions show a good agreement with experimental results with less than $8 \%$ of error for the 22 defects case and less than $5 \%$ for the 44 defects case. Furthermore, predictions show that the decrease in fatigue limit slows down with the increase of defect number. The probabilistic model predicts that after a number of defects around 30, fatigue limit decrease is no longer significant. This tendency is usual for statistical size effect $[1,12]$.

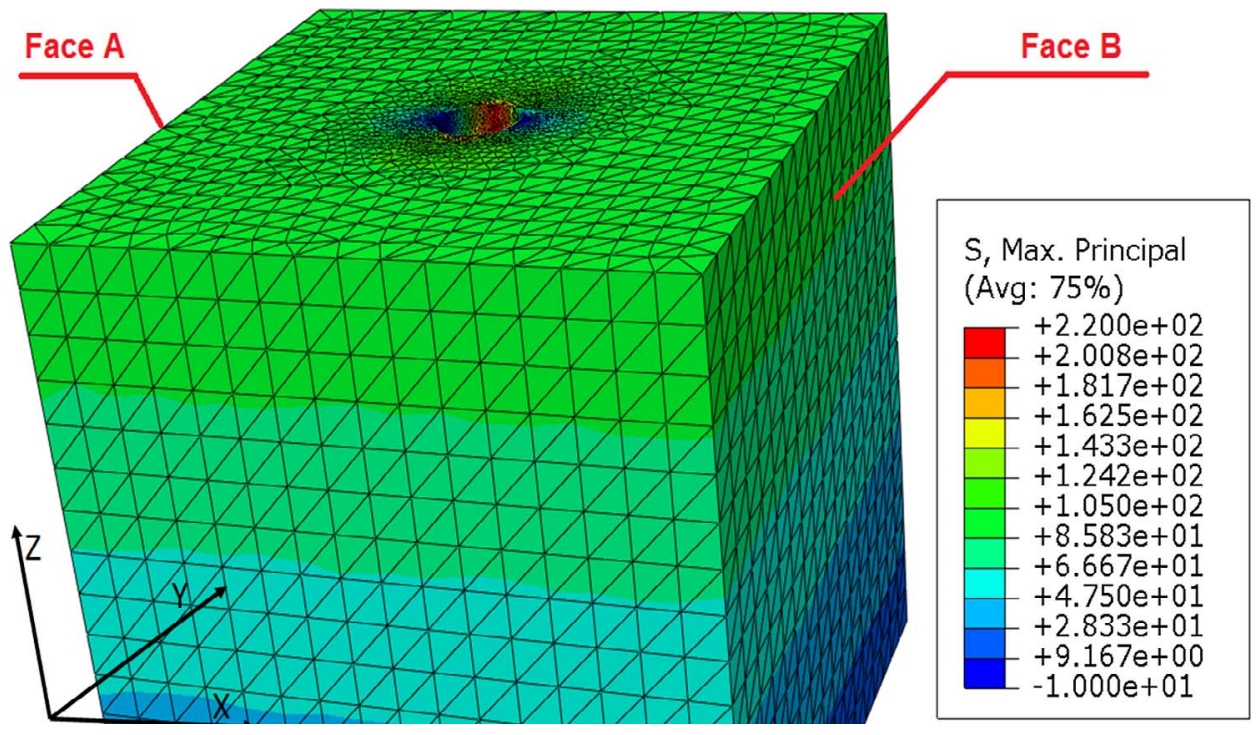

Fig. 16. FE simulation of a cube with hemispherical defect under bending loading. 

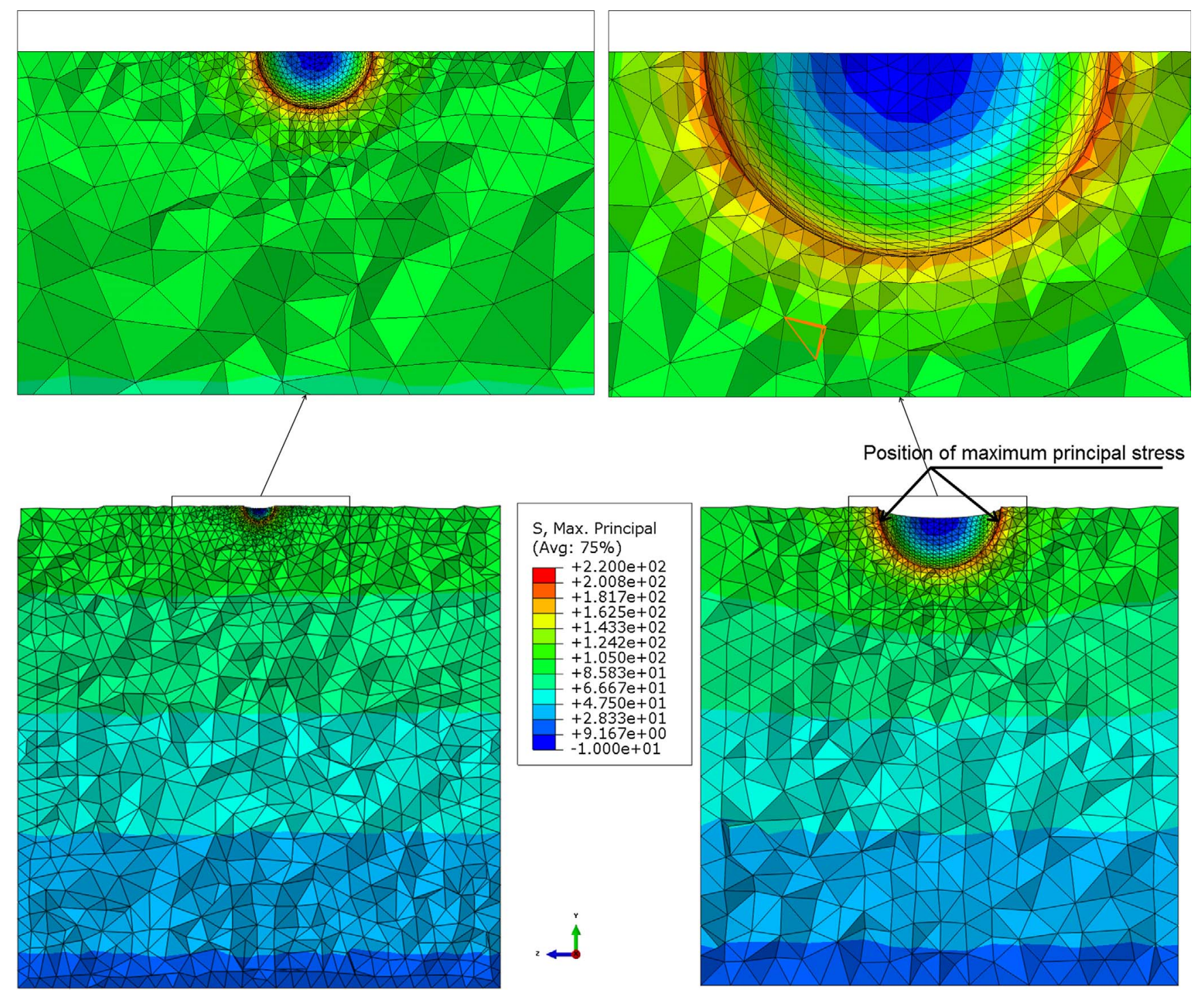

Fig. 17. Stress distribution in case of a $\emptyset 200 \mu \mathrm{m}$ and $\emptyset 800 \mu \mathrm{m}$ defect. The surface applied stress is $100 \mathrm{MPa}$.

a

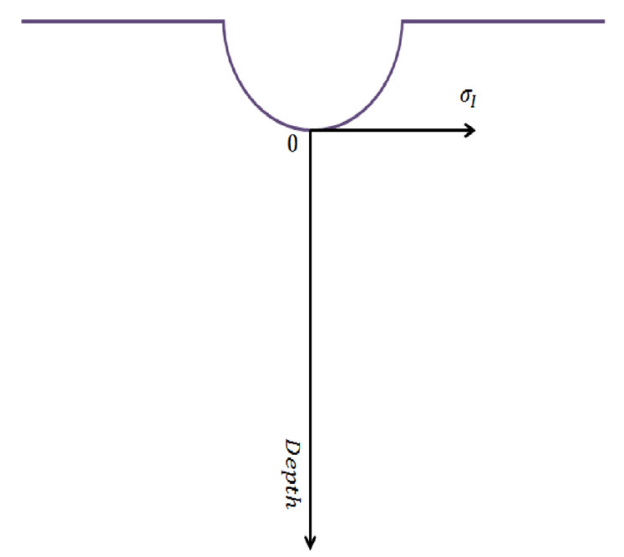

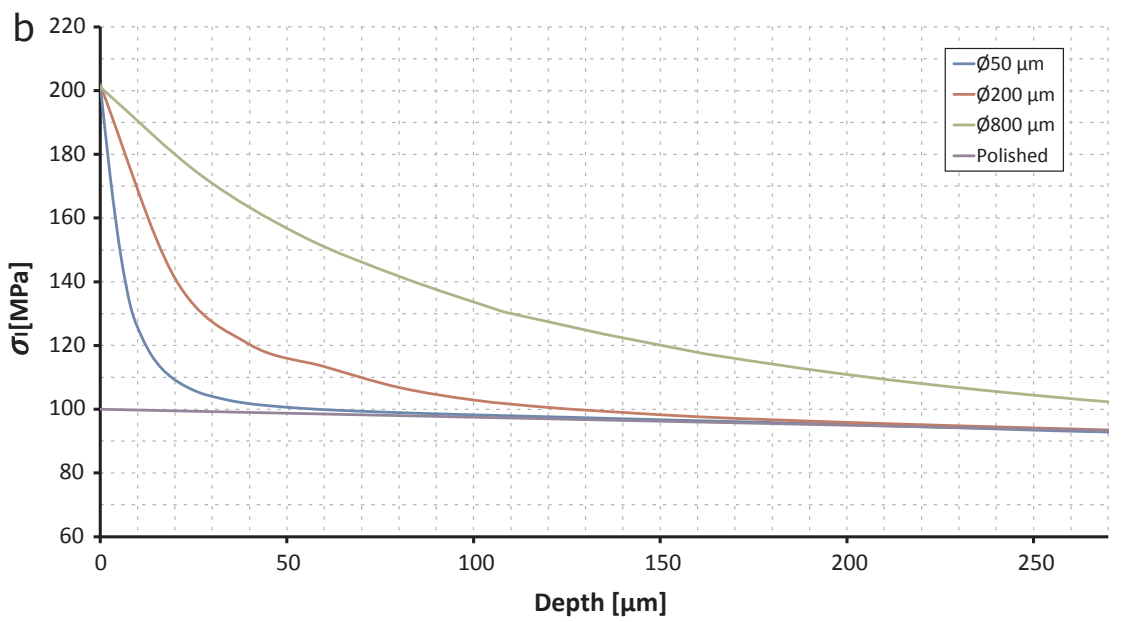

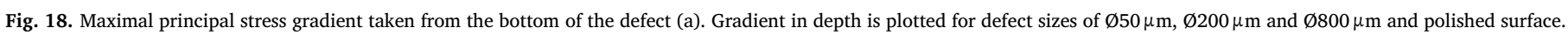
The surface applied stress is $100 \mathrm{MPa}$. 

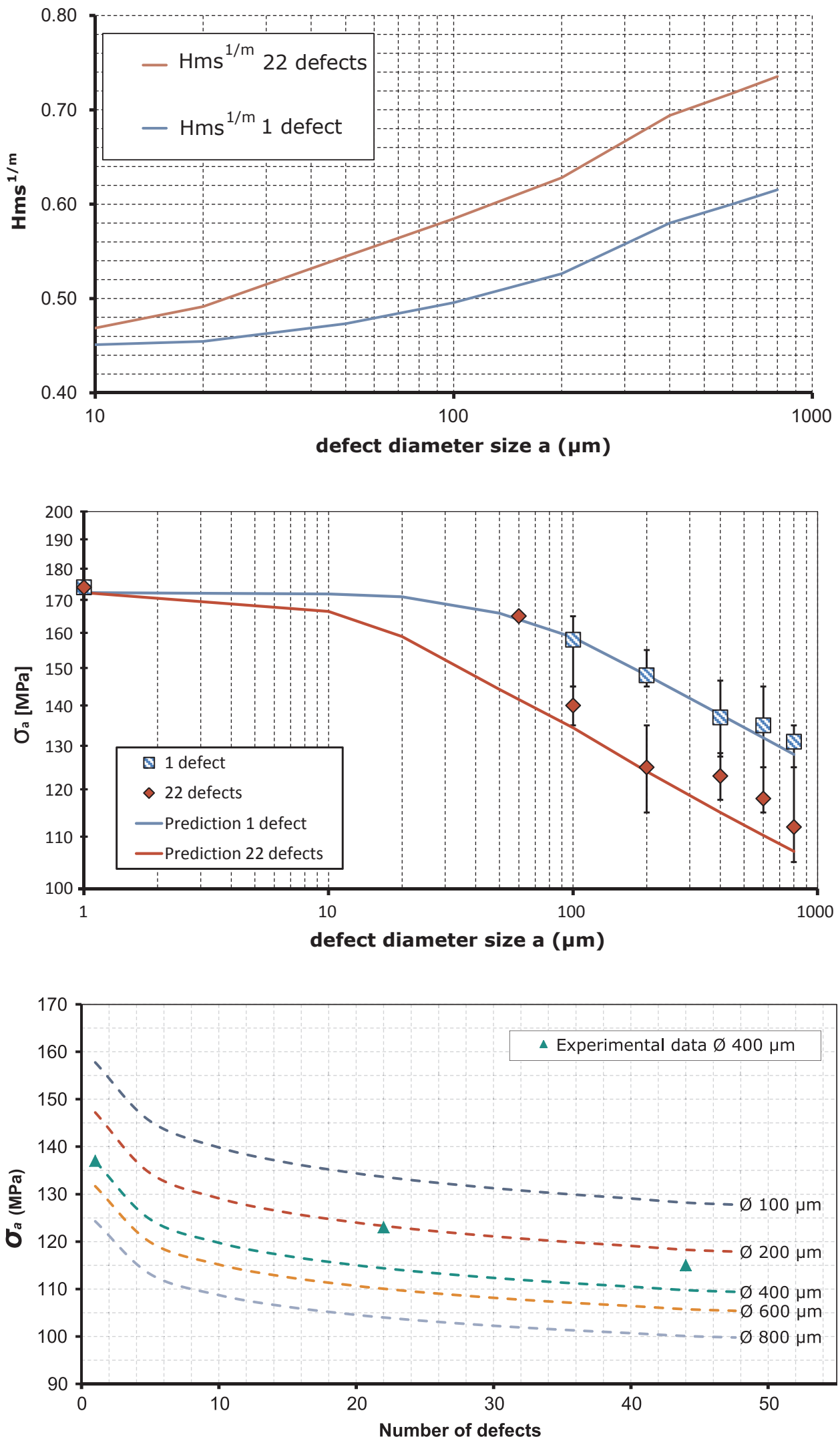

Fig. 19. Evolution of $H_{m s}^{1 / m}$ with the defect size for a specimen containing 1 and 22 defects.

Fig. 20. Predictions of fatigue behaviour using a surface approach.
Fig. 21. Comparison between experimental results for $\emptyset 400 \mu \mathrm{m}$ specimen with different defects number and predictions of fatigue limit using the surface approach.

\subsection{Predictions using a volume approach}

The surface approach allows good predictions of the fatigue limit in presence of defects of different size and number apart from defects smaller than $\varnothing 100 \mu \mathrm{m}$ where predictions are too conservative. This could be due to the fact that the surface approach only considers the stress on the extreme surface of the specimen. Thus, even the smallest size defect has an impact on the predicted fatigue limit which is clearly not the case. In literature, some studies $[7,8,11]$ consider the stress not in the highly stressed point but at a given distance or in a non local way 

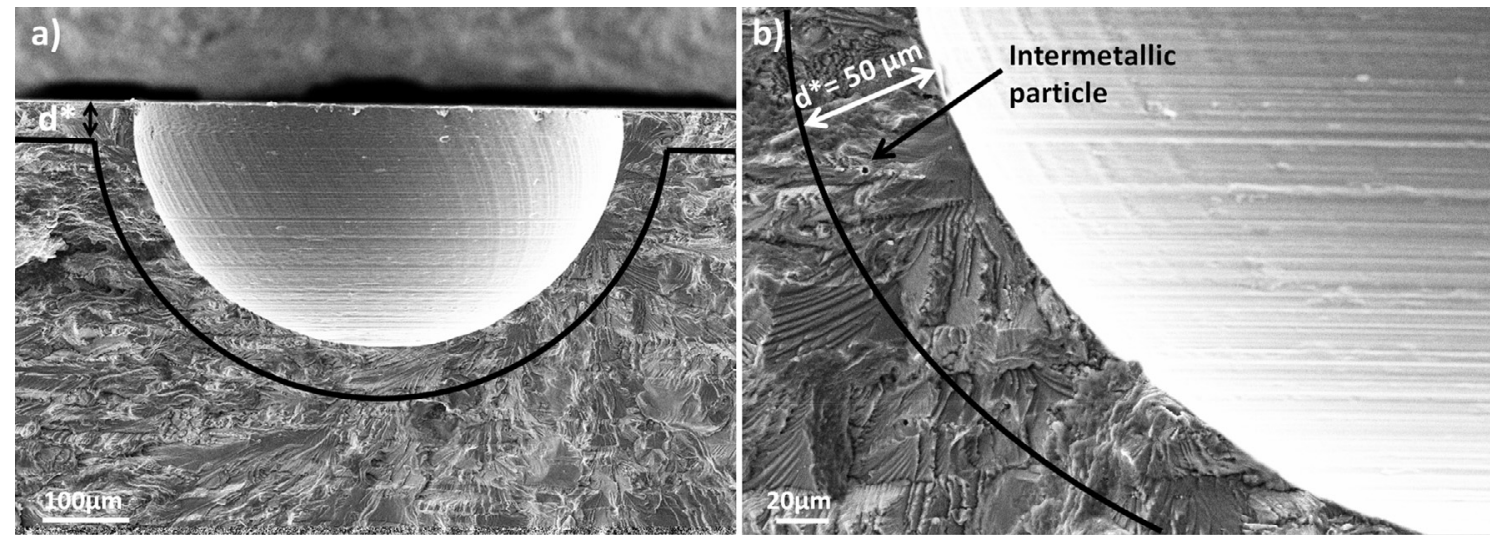

Fig. 22. Illustration of the $d^{*}$ parameter on the specimen D600-1-4 failure surface, $d^{*}=50 \mu \mathrm{m}$.

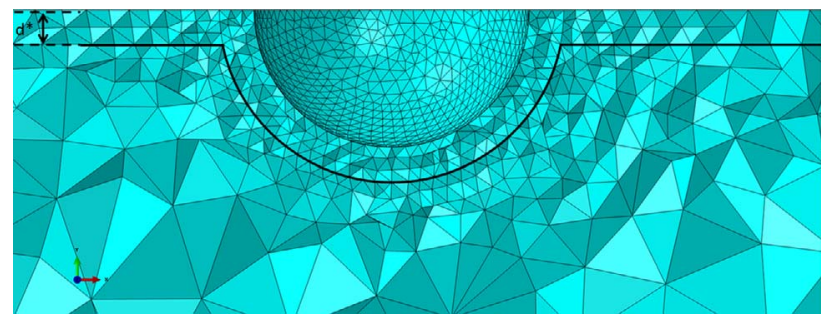

Fig. 23. Illustration of the $d^{*}$ parameter in the Finite Element Model.

as a mean value over a given volume. This is a simple way to reflect the asymptotic response of small defects.

For the proposed approach, the stress distribution is considered in a domain consisting of a volume $V_{\Omega}$ with a constant depth $d^{*}$ from the free surface $S_{\Omega}$ (see Fig. 23). Failure surface observations show that intermetallic particles are mostly localized in the first $50 \mu \mathrm{m}$ in depth. Based on these experimental observations, a value of $d^{*}$ equal to $50 \mu \mathrm{m}$ is used to reflect the possibility to have an intermetallic particle at the initiation site (see Figs. 22 and 23).

For the volume formulation, stress heterogeneity factor $H_{m v}$ is expressed as follows:

$H_{m v}=\frac{1}{V_{\Omega}} \int_{V_{\Omega}}\left(\frac{\sigma_{e q}}{\sigma_{\max }}\right)^{m} d V$

where $\sigma_{\max }$, the maximum equivalent stress on the component volume: $\sigma_{\max }=\max _{V_{\Omega}}\left(\sigma_{e q}\right)$

In the same way as in the previous paragraph, fatigue limit can hence be predicted as:

$\sigma_{a}=\frac{\sigma_{0}}{K_{t_{\max }}}\left[\frac{V_{0}}{V_{\Omega}} \frac{\ln \left(\frac{1}{1-P_{F}}\right)}{H_{m v}}\right]^{1 / m}$

with $V_{0}$ represents the reference volume.

Like in the surface approach simulation, the specimen volume is divided in different cells containing defect or not. The stress hetereogeneity factor $H_{m v}$ can be expressed as a combination of $H_{m v_{d}}$ and $H_{m v_{p}}$ :

$H_{m v}=\frac{1}{V_{\Omega}}\left[n V_{d} H_{m v_{d}}+\frac{V_{\Omega}-n V_{d}}{K_{t_{\max }^{m}}^{m}} H_{m v_{p}}\right]$

with $H_{m v_{d}}$ the stress heterogeneity factor of a cell containing a defect and $H_{m v}$ the stress heterogeneity factor of a cell without a defect.

The experimental point taken as reference for the identification procedure is the case of 1 defect of $\emptyset 400 \mu \mathrm{m}$. As shown in Fig. 24, different couples $\left(m, \sigma_{0}\right)$ allow to predict the fatigue strength of 1 defect of $\varnothing 400 \mu \mathrm{m}$ batch. The one that provides the lower error value between predictions and experimental results is the couple $\left(m=22 ; \sigma_{0}=226 \mathrm{MPa}\right)$.

Fig. 25 shows that the volume approach keeps the advantages provided by the surface approach in describing the fatigue behavior in

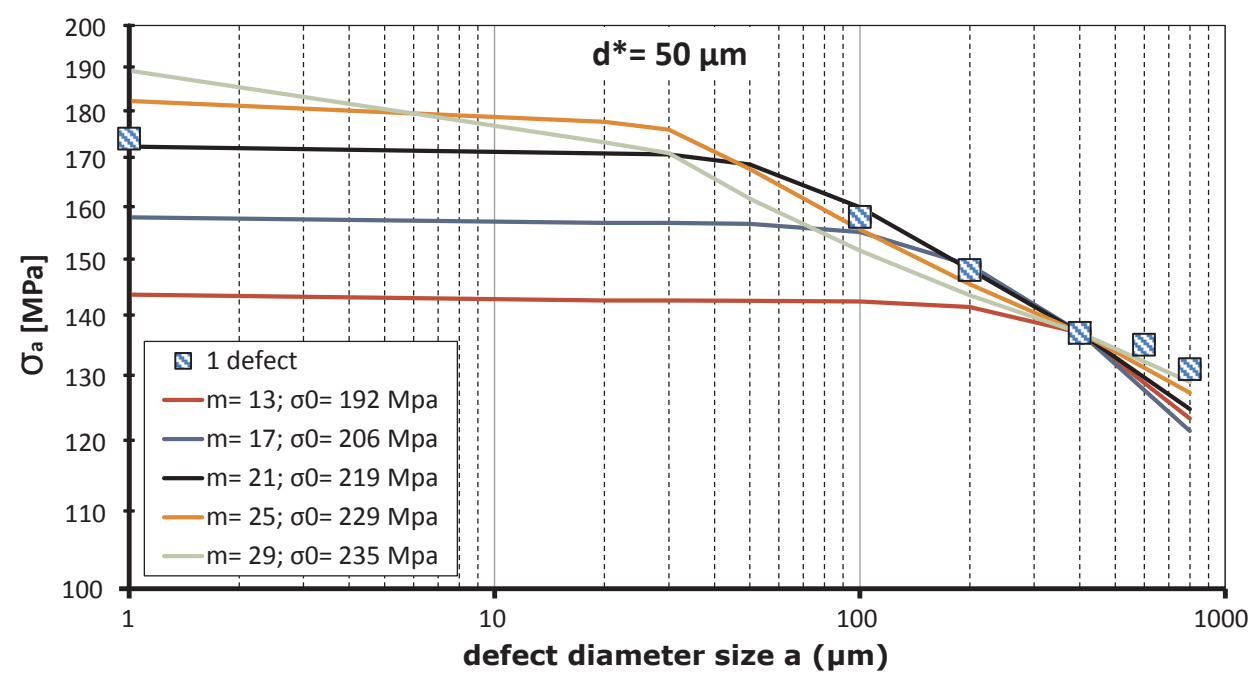

Fig. 24. Identification of the couple model parameter $\left(m ; \sigma_{0}\right)$ used in the volume approach. 

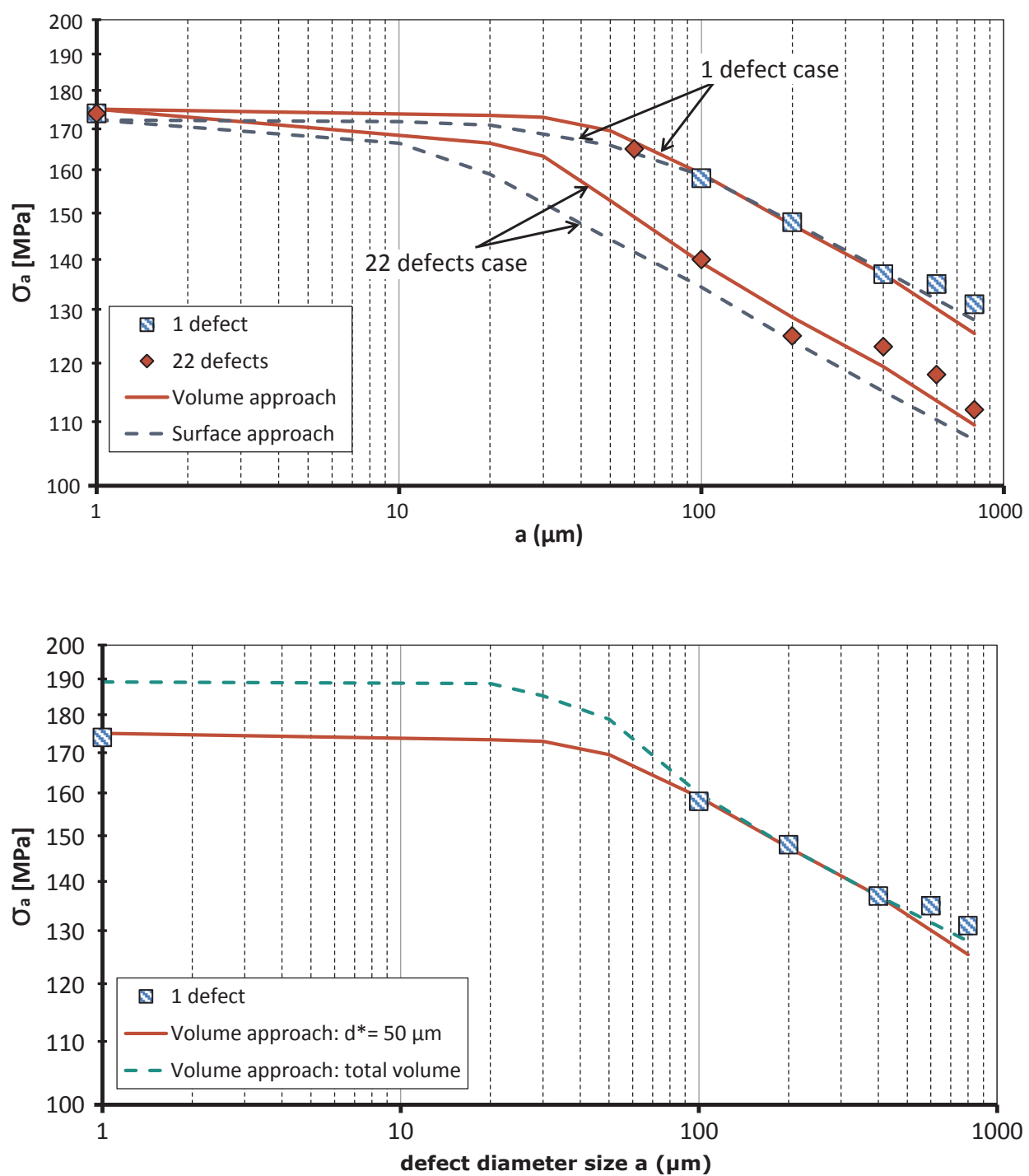

Fig. 25. Predictions of fatigue behaviour using a surface and a volume approach.
Fig. 26. Predictions of fatigue strength using a volume and a total volume approach. presence of different size and number of defects. Predictions are in good agreement with experimental results and reflect well the drop of the fatigue limit with the increase of the size and the number of defects. Also, volume approach allows to successfully predict fatigue limit of a component without defect. In addition, it predicts the fatigue limit in presence of small defects in a better way and reduces the error in case of $\emptyset 60 \mu \mathrm{m}$ from $15 \%$ for the surface method to $9 \%$.

Using a defined volume and not the entire component could be questionnable because this approach does not take into account the probability that initiation could occur in the total volume of material. To discuss this specific question, calculation have been conducted considering the total specimen volume. The identified model parameters, using the same procedure previously presented are $m=38, \sigma_{0}=207 \mathrm{MPa}$ and $d^{*}=+\infty$. The predictions obtained using the previous approach and the total volume approach are compared in Fig. 26. The total volume approach cannot predict the fatigue strength of the polished specimens without defects. A possible explanation is related to the fact that crack initiation in fatigue is mostly a surface phenomenon. At the local scale the crack initiation threshold is therefore probably higher in the bulk of the material compared to the surface. Fig. 26 illustrates that using the same Weibull distribution for the total component, i.e in the bulk and on the surface gives less accurate predictions.

\section{Analysis and conclusion}

The main conclusions of this work are:

- An original fatigue tests campaign have been conducted in order to identify the scale effect and the defect size effect on fatigue behaviour of AA7050 alloy. Fully reversed plane bending fatigue tests have been conducted on specimens with differents size and number of hemispherical defects.

- Fatigue limit decreases gradually when increasing defect size. Furthermore, another decrease in fatigue limit is observed when increasing defects number (scale effect).

- The proposed approach based on Weibull's distribution law and the weakest link concept allows to predict the fatigue limit for polished specimens as well as specimens with a single or several artificial defects. Fatigue limit predictions are in good agreement with the experimental results.

- Volume approach shows better predictions than surface approach and allows to reflect the asymptotic behavior for small defects.

The experimental results and the developed approach illustrate the importance of taking the scale effect into account when designing 
components containing several surface defects. The proposed criterion could be a useful tool when designing components containing different surface defects types or roughness patterns. As prospects, the proposed criterion will be applied to industrial machined surfaces with different roughness patterns.

\section{Aknowledgments}

This work was carried out within the FUI QUAUSI project with the support of industrial (Dassault Aviation, Europe Technologie, Figeac Aéro, Mecachrome, Spring Technologie, Precise, GEBE2, CETIM) and academic partners (LSN2-IUT Carquefou).

\section{References}

[1] Papadopoulos IV. Gradient-dependent multiaxial high-cycle fatigue criterion. In: Pineau A, Cailletaud G, Lindley TC, editors. Multiaxial fatigue and design, ESIS 21. London: Mechanical Engineering Publications; 1996. p. 349-64.

[2] Murakami Y, Usuki H. Quantitative evaluation of effects of non-metallic inclusions on fatigue strength of high strength steels. II: Fatigue limit evaluation based on statistics for extreme values of inclusion size. Int J Fatigue 1989;11(5):299-307.

[3] Makkonen L, Rabb R, Tikanmäki M. Size effect in fatigue based on the extreme value distribution of defects. Mater Sci Eng A 2014:594:68-71.

[4] ASTM E2283-03. Standard practice for extreme value analysis of nonmetallic inclusions in steel and other microstructural features. West Conshohocken (PA): ASTM International; 2003.

[5] Freudenthal AM. Liebowitz H, editor. Fracture, vol. 2. New York: Academic Press; 1968. p. 591-619.

[6] Weibull W. A statistical distribution function of wide applicability. ASME J Appl Mech 1951;18:293-7.

[7] Taylor D. Geometrical effects in fatigue: a unifying theoretical model. Int J Fatigue 1999;21(5):413-20.

[8] Taylor D. The theory of critical distances. Eng Fract Mech 2008;75(7):1696-705.

[9] Taylor D. A mechanistic approach to critical-distance methods in notch fatigue. Fatigue Fract Eng Mater Struct 2001;24(4):215-24.

[10] Le VD, Saintier N, Morel F, Bellett D, Osmond P. Investigation of the effect of porosity on the high cycle fatigue behaviour of cast Al-Si alloy by X-ray microtomography. Int J Fatigue 2018;106:24-37.

[11] Gerin B, Pessard E, Morel F, Verdu C. A non-local approach to model the combined effects of forging defects and shot-peening on the fatigue strength of a pearlitic steelthe. Theor Appl Fract Mech 2017:2008.

[12] Delahay T, Palin-Luc T. Estimation of the fatigue strength distribution in high-cycle multiaxial fatigue taking into account the stress-strain gradient effect. Int J Fatigue 2006;28:474-84.
[13] Flaceliere L, Morel F. Probabilistic approach in high-cycle multiaxial fatigue: vo lume and surface effects. Fatigue Fract Eng Mater Struct 2004;27(12):1123-35.

[14] Morel F, Huyen N. Plasticity and damage heterrogeneity in fatigue. Theor Appl Fract Mech 2008;49:98-127.

[15] luu DH, Maitournam MH, Nguyen QS. Formulation of gradient multiaxial fatigue criteria. Int J Fatigue 2014;61:170-83.

[16] Brunet $\mathrm{S}$. PhD thesis: Influence des contraintes résiduelles induites par usinage sur la tenue en fatigue des matériaux métalliques aéronautiques, Paris, FRANCE: ENSAM Paris; 1991.

[17] Suraratchaï M, Limido J, Mabru C, Chieragatti R. Modelling the influence of machined surface roughness on the fatigue life of aluminum alloy. Int $J$ Fatigue 2008;30:2119-26.

[18] Shahzad M, Chaussumier M, Chieragatti R, Mabru C, Rezai Aria F. Influence of anodizing process on fatigue life of machined aluminium alloy. Proc Eng 2010;2:1015-24.

[19] Gupta VK, Agnew SR. Fatigue crack surface crystallography near crack initiating particle clusters in precipitation hardened legacy and modern $\mathrm{Al}-\mathrm{Zn}-\mathrm{Mg}-\mathrm{Cu}$ alloys. Int J Fatigue 2011;33(9):1159-74.

[20] Dixon WJ, Mood AM. A method for obtaining and analyzing sensitivity data. J Am Stat Assoc 1948;43:108-26.

[21] ISO12107:2012: metallic materials - fatigue testing - statistical planning and analysis of data.

[22] Maxwell DC, Nicholas T. A rapid method for generation of a Haigh diagram for high cycle fatigue. Panontin TL, Sheppard SD, editors. Fatigue and fracture mechanics, ASTM STP 1321, vol. 29. West Conshohocken (PA): American Society for Testing and Materials; 1999. p. 626-41.

[23] Pessard E, Morel F, Bellet D, Morel A. A new approach to model the fatigue anisotropy due to non-metallic inclusions in forged steels. Int J Fatigue 2012;41:168-78.

[24] Shahzad M, Chaussumier M, Chieragatti R, Mabru C, Rezai-Ari F. Surface characterization and influence of anodizing process on fatigue life of $\mathrm{Al} 7050$ alloy. Mater Des 2011;32(6):3328-35.

[25] Chaussumier M, Mabru C, Shahzad M, Chieragatti R, Rezai-Ari F. A predictive fatigue life model for anodized 7050 aluminium alloy. Int J Fatigue 2013;48:205-13.

[26] Kitagawa H, Takahashi S. Applicability of fracture mechanics to very small cracks. In: ASM Proceedings of 2nd international conference on mechanical behaviour of materials. Metalspark (Ohio); 1976. p. 627-731.

[27] Murakami Y. Metal fatigue: effects of small defects and nonmetallic inclusions Elsevier; 2002

[28] Li JF, Zheng ZQ, Li SC, Chen WJ, Zhao XS. Simulation study on function mechanism of some precipitates in localized corrosion of $\mathrm{Al}$ alloys. Corros Sc 2007;49:2436-49.

[29] Sauzay M, Evrard P, Steckmeyer A, Ferrié E. Physically-based modeling of the cyclic macroscopic behaviour of metals. Proc Eng 2010;2:531-40.

[30] Guerchais R, Robert C, Morel F, Saintier N. Micromechanical study of the loading path effect in high cycle fatigue. Int J Fatigue 2014;59:64-75.

[31] Weibull W. A statistical theory of the strength of materials. Roy. Swed. Inst. Eng. Res. Report 151; 1939. 